\title{
The Current Role of Graphene-Based Nanomaterials in the Sample Preparation Arena
}

\author{
Edvaldo Vasconcelos Soares Maciel, Karen Mejía-Carmona, Marcela Jordan-Sinisterra, \\ Luis Felipe da Silva, Deyber Arley Vargas Medina and Fernando Mauro Lanças* \\ Laboratory of Chromatography (CROMA), São Carlos Institute of Chemistry (IQSC), University of São Paulo, São Carlos, \\ Brazil
}

Since its discovery in 2004 by Novoselov et al., graphene has attracted increasing attention in the scientific community due to its excellent physical and chemical properties, such as thermal/mechanical resistance, electronic stability, high Young's modulus, and fast mobility of charged atoms. In addition, other remarkable characteristics support its use in analytical chemistry, especially as sorbent. For these reasons, graphene-based materials (GBMs) have been used as a promising material in sample preparation. Graphene and graphene oxide, owing to their excellent physical and chemical properties as a large surface area, good mechanical strength, thermal stability, and delocalized $\pi$-electrons, are ideal sorbents, especially for molecules containing aromatic rings.

OPEN ACCESS

Edited by:

Cosimino Malitesta

University of Salento, Italy

Reviewed by:

Antonella Profumo,

University of Pavia, Italy

Javier Hernández-Borges,

University of La Laguna, Spain

*Correspondence:

Fernando Mauro Lanças

flancas@iqsc.usp.br

Specialty section:

This article was submitted to

Analytical Chemistry,

a section of the journal

Frontiers in Chemistry

Received: 17 April 2020

Accepted: 26 June 2020

Published: 11 August 2020

Citation:

Maciel EVS, Mejía-Carmona K,

Jordan-Sinisterra M, da Silva LF,

Vargas Medina DA and Lanças FM

(2020) The Current Role of

Graphene-Based Nanomaterials in the

Sample Preparation Arena.

Front. Chem. 8:664.

doi: 10.3389/fchem.2020.00664
They have been used in several sample preparation techniques such as solid-phase extraction (SPE), stir bar sorptive extraction (SBSE), magnetic solid-phase extraction (MSPE), as well as in miniaturized modes as solid-phase microextraction (SPME) in their different configurations. However, the reduced size and weight of graphene sheets can limit their use since they commonly aggregate to each other, causing clogging in high-pressure extractive devices. One way to overcome it and other drawbacks consists of covalently attaching the graphene sheets to support materials (e.g., silica, polymers, and magnetically modified supports). Also, graphene-based materials can be further chemically modified to favor some interactions with specific analytes, resulting in more efficient hybrid sorbents with higher selectivity for specific chemical classes. As a result of this wide variety of graphene-based sorbents, several studies have shown the current potential of applying GBMs in different fields such as food, biological, pharmaceutical, and environmental applications. Within such a context, this review will focus on the last five years of achievements in graphene-based materials for sample preparation techniques highlighting their synthesis, chemical structure, and potential application for the extraction of target analytes in different complex matrices.

Keywords: graphene, graphene oxide, cyclodextrin, molecularly-imprinted polymer, magnetic, ionic liquid, sample preparation

\section{INTRODUCTION}

Over the last decades, nanotechnology has become a promising tool in relevant scientific fields, allowing humanity to reach top levels of quality in several areas such as engineering, chemistry, medicine, and sports, among others (Lin et al., 2019). One of the most significant achievements in this context was the confirmation of the existence of a single-layered graphene sheet obtained 
through mechanical exfoliation by Novoselov et al. in 2004 at Manchester University (Novoselov, 2004; Novoselov et al., 2005). The history of graphene $(G)$ starts $\sim 70$ years ago when Landau and Peierls stated that strictly 2D crystals were thermodynamically unstable with a slight likelihood even to exist (Peierls, 1935; Landau, 1937). At that time, the scientists thought that the melting point of a thin-film of atoms decreased proportionally to its thickness leading to structure decomposition or segregation (Peierls, 1935; Landau, 1937). Therefore, the atomic monolayers' existence would only be possible to exist as an epitaxially-grown part of $3 \mathrm{D}$ complex structures. Nonetheless, this theory was confronted by experimental observations reported in 2004, which preceded the discovery of more than one type of $2 \mathrm{D}$ atomic monolayers, highlighting graphene as the most important of them (Geim and Novoselov, 2007). For this reason, graphene theoretically represents a new class of materials possessing a one-atom thickness that, due to its intrinsic properties, are creating new possibilities of practical applications and becoming a hot topic in science.

Graphene can be defined as a carbon allotrope composed by a structure containing $\mathrm{sp}^{2}$ hybridized atoms obeying a honeycomb pattern, which is the core for other widely-known allotropic forms (Grajek et al., 2019). In other words, graphene can be stacked to form graphite, rolled to form a carbon nanotube, or even wrapped to become a fullerene, as shown in Figure 1. In general, it is considered a wonder material due to its nanosheet structure, which has strong $\sigma$-orbitals in the $2 \mathrm{D}$ plane, ensuring its stiffness. At the same time, the un-hybridized $\pi$-orbitals are hinged outwards, superimposing one by one to form the long-range delocalized $\pi$ electron system, responsible for its outstanding optical, and electrical properties (Grajek et al., 2019). In short, unmodified graphene sheets have a large theoretical surface area (ca. $2630 \mathrm{~m}^{2} \mathrm{~g}^{-1}$ ) distributed along with the thinnest structure of the negligible mass, but high Young's modulus, as already discovered (Fumes et al., 2015). Likewise, its charge carriers have high mobility, possibly traveling micrometers without scattering, becoming an ideal material for producing electronic devices (Hou et al., 2019). Moreover, the excellent thermal and electrical conductivity $\left(\sim 3,000 \mathrm{~W} \mathrm{mK}^{-1}\right.$ and 104 $\Omega^{-1} \mathrm{~cm}^{-1}$, respectively), transparency, and impermeability to gases must be underscored (Geim, 2009).

Although these top qualities suggest that graphene would be an ideal material with several different potential applications, the manufacturing (especially in industrial-scale) still represents a hurdle to its broad implementation. This occurs because the most utilized manufacturing approach is based on the graphite top-down mechanical exfoliation process by adhesive tape (Allen et al., 2010). Generally, this production method is laborious, non-reproducible, and highly dependent on human handling. It has attracted the chemists' interest in developing scalable alternative routes to produce significant amounts of highquality graphene nanosheets. Including on this are the chemical exfoliation through liquid solutions, the bottom-up method to produce from organic precursors, among others (Allen et al., 2010; Vadivel et al., 2017). It must be noted that each of these alternative production methods has its proper characteristics. The chemical exfoliation provides interesting results regarding the quality of graphene nanosheets or even due to the existence of intermediary graphene-based compounds similarly attractive for such purposes, such as the graphite oxide or graphene oxide, for instance.

Even with the graphene existence being confirmed since 2004, its first application in sample preparation was only published in 2011 (Luo et al., 2011a; Zhang and Lee, 2011). The interest of analytical chemists on it and its derivatives is mostly due to the increasing demand for high-performance and selective materials to extract contaminants present in complex matrices containing a large number of interferents. The present outlook of our environment urges researchers to seek technological advances on sample preparation and analytical techniques to tackle even better the increasing use of chemicals by humans in many areas of life: agriculture, health-treatments, and abusive-drugs, among others. Within such a context, the necessity in performing a sample preparation step before the analytical techniques is mandatory due to the complexity related to the mostly analyzed matrices (biological fluids, food, plants, wastewaters, soil, and others). This step is crucial in the analytical workflow

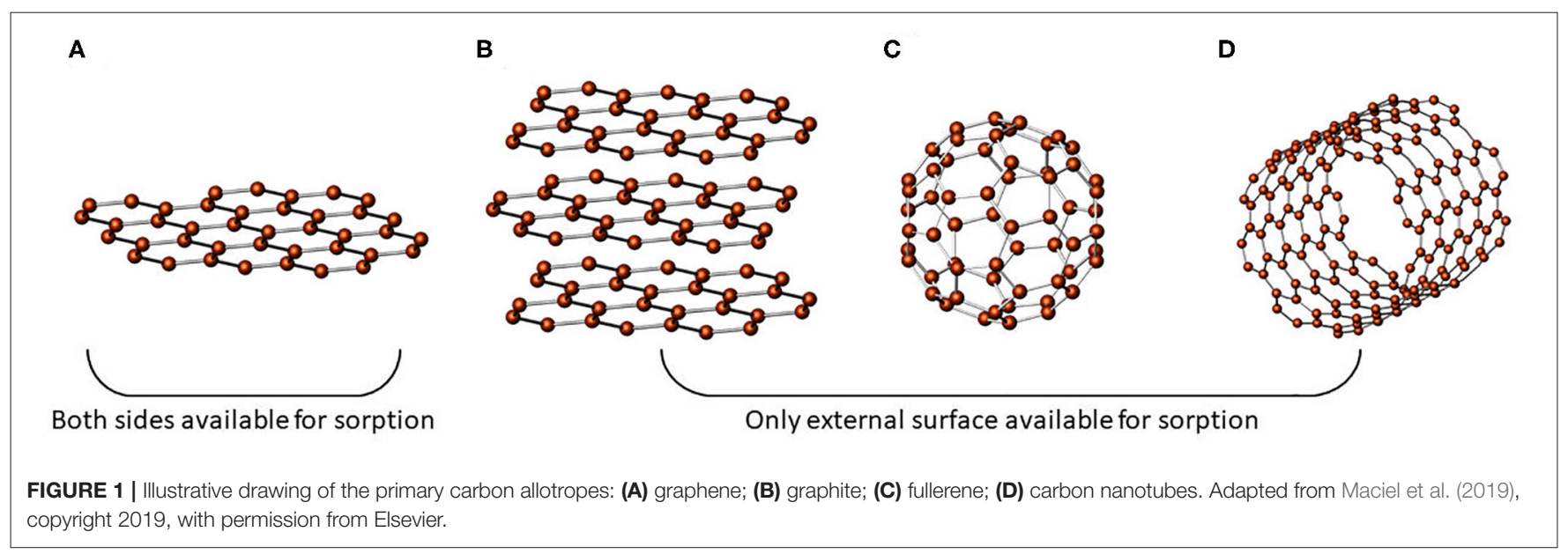


responsible for eliminating matrix interferents, isolating, and pre-concentrating target analytes. For these reasons, several different sorption-based sample preparation techniques (e.g., microextraction by packed sorbent [MEPS], stir bar sorptive extraction [SBSE], magnetic solid-phase extraction [MSPE], among others) have been proposed. They are mostly derived from conventional SPE and its main miniaturized mode SPME (Fumes et al., 2015). Generally, they are performed by the employment of an extractive phase, usually named as sorbent. Ideally, this sorbent must present some essential characteristics such as good selectivity to the target compounds, high extraction capability, and even is desirable as a chemical inertia for those interferents present in the analyzed matrix (Toffoli et al., 2018).

Then, GBMs emerged as promising sorbents to be used in the extraction techniques, due to its chemical structure and properties, which favors the extraction performance by effectively removing the target analytes from complex matrices. Considering all the advantages herein presented, some of them are more interesting from the analytical chemistry standpoint. For example, the flat graphene structure allows potential target analytes to interact on both sides of it, which is advantageous for sorption-based sample preparation techniques. In the case of other carbon allotropes (e.g., carbon nanotubes, graphite, and fullerene), only the external surface is available for such interaction, which potentially diminishes extraction performance due to this steric hindrance associated. Additionally, the delocalized $\pi$-electron system favors electrostatic interaction between the graphene and molecules that possess aromatic rings in its structure.

For this reason, prevalent contaminants such as pesticides, preservatives, pharmaceuticals, and veterinary drugs can be remediated from the environment by using GBMs (Toffoli et al., 2018). Contrariwise, when the potential contaminant does not have aromatic rings, a functional intermediary produced from the chemical exfoliation, namely graphene oxide (GO), can be used instead of graphene. This is owing to its chemical structure that differs from $G$ by the presence of oxygenated groups (e.g., hydroxyl, carbonyl, alkoxy) outside of its 2D-plane, possibly favoring interactions with polar active-sites in other molecules (Smith et al., 2019). Nonetheless, from an operational point of view, the fact that graphene is an ultra-light material makes difficult its deposition by, for example, centrifugation. In this way, some chemical modification or functionalization can be performed to overcome such drawbacks. Nowadays, other carbon-based compounds that possess one-atom planar structures are beginning to spur around, mainly due to the attention given to the scientific community's graphene in the last years. Including in this group are graphyne, graphdiyne, graphone, and graphane, all considered as graphene-derivative compounds (Peng et al., 2014). As an example, graphyne and graphdiyne are 2D-flat allotropic forms of graphene possessing the same honeycomb pattern, which suggests them as suitable for similar applications as its precursor (graphene).

Conversely, graphone and graphene emerged as hydrogenated graphene-derivative compounds susceptible to chemical modifications onto its surfaces. Despite these compounds already discussed in the literature, their synthesis remains a complicated process; for this reason, they have not yet been applied in sample preparation. However, considering the significant advances in graphene-based technologies since its discovery, these other allotropic forms might gain more attention from scientists throughout the years.

Following the background regarding the emerging of graphene, this review aims to present the state-of-art about this "wonder material" from a sample preparation viewpoint. In this way, several aspects such as synthesis and functionalization process, the main derivative classes, and its most suitable applications are divided among the next sections. In short, our primary goal was to present a review mostly covering the last 5 years' achievements of the still-evolving field of graphene-based materials in sample preparation and discuss the future trends and potential challenges that chemists should face in the years to come.

\section{GRAPHENE AND GRAPHENE OXIDE}

As mentioned, graphene $(\mathrm{G})$ is a $2 \mathrm{D}$ monolayer of carbon atoms covalently bonded in a honeycomb pattern, displaying a flat sheet conformation (Solís-Fernández et al., 2017). Graphene and related materials are part of the graphene-based materials (GBMs), which comprises graphene $(\mathrm{G})$ nanosheets (in mono, few, and multi-layers), graphene oxide (GO), and reduced graphene oxide (rGO) (De Marchi et al., 2018). A considerable variety of research articles about different synthesis methods, properties, and applications of GBMs are available (Papageorgiou et al., 2017; Lim et al., 2018; Liu and Zhou, 2019). Two different approaches can be used to obtain graphene: (i) the top-down, in which nanostructures are produced from larger dimensions, and (ii) the bottom-up, starting from atoms or small molecules to produce materials of larger dimensions.

In the top-down approach, graphene is prepared from graphite, by mechanical or chemical exfoliation, or chemical synthesis, separating the graphene thin layers parallelly stacked in the graphite and held together by weak van der Waals forces. Mechanical exfoliation is one of the simplest methods in which a simple direct contact with an adhesive tape (polymer) can take off the graphene layers from the surface of a graphite piece. One of the advantages of mechanical exfoliation is the possibility of different pile-up layers of other 2D materials with several graphene heterostructures (Solís-Fernández et al., 2017). However, it has only been implemented on a small scale and is highly susceptible to contamination. In the same way, organic solvents can be used to separate the graphite layers. Other exfoliation methods include the use of electric fields, sonication, and transfer printing technique (Lim et al., 2018). Several exfoliation methods, including different substrates, thermal released tape, and thermal approaches, have been proposed to improve the quality, size, and homogeneity of graphene (Solís-Fernández et al., 2017).

Chemical reduction of graphene oxide (GO) is the most popular method to obtain graphene. As shown in Figure 2, GO can be obtained by the oxidation of graphite powder and then exfoliated further to obtain single GO layers, which is 


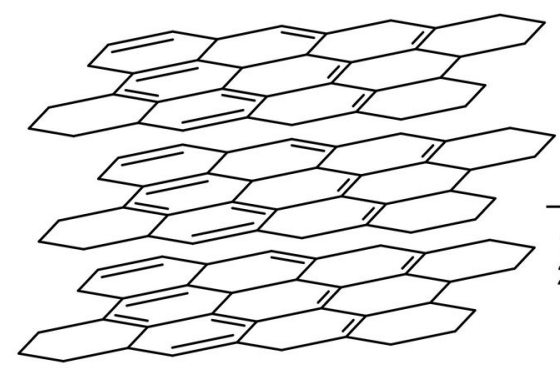

Graphite

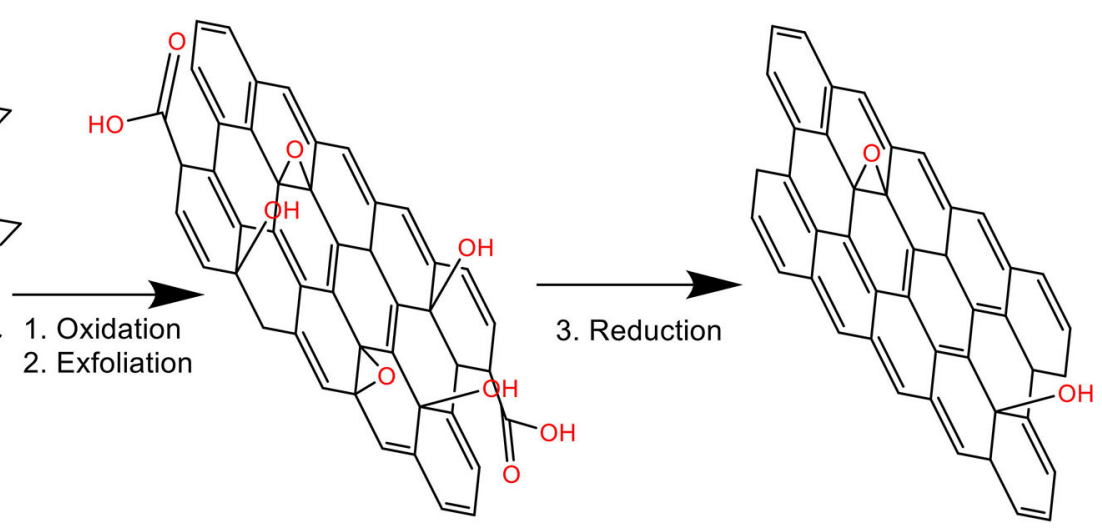

Graphene oxide (GO)
Reduced Graphene (rGO)

FIGURE 2 | Graphene chemical reduction pathway.

subsequently chemically reduced to obtain rGO. Although the final product obtained from this pathway is $\mathrm{rGO}$, its properties are very similar to graphene but are structurally different (Dreyer et al., 2010; Singh et al., 2016). Chemical reduction of GO firstly involves exfoliation in water assisted by ultrasonication, followed by reduction of the oxygenated groups, hence precipitating the rGO from the solution due to its hydrophobicity (Singh et al., 2016). Among the wide variety of chemical reduction agents that can be employed, hydrazine is the most often used because of its high reductive efficiency, even though it is highly environmental toxic. As an alternative, the use of greener reduction agents (De Silva et al., 2017) and thermally-mediated or electrochemical reduction are also employed. Although chemical reduction of GO is a popular upscaling method, it yields a final product containing several structural defects on the sheets, which lead to low-quality materials with variable sizes and edges (Dreyer et al., 2010).

Conversely, the bottom-up approaches are another alternative to synthesize high-quality graphene layers. The leading methods used include pyrolysis, chemical vapor deposition (CVD), plasma synthesis, and epitaxial growth (Lim et al., 2018). Graphene sheets are prepared from small building blocks and assembled with dedicated precision, usually employing molecular modeling to build the layers. Among the bottom-up methods, CVD uses high temperatures for the decomposition of hydrocarbons, which are deposited on metal substrates, thus forming thin sheets of graphene (Papageorgiou et al., 2017). The main advantage of bottom-up methods is the production of high-quality graphene sheets. Nevertheless, these methods are not used for largescale production.

Graphene oxide (GO) is like a graphene sheet functionalized on both sides with several oxygenated functions such as hydroxyl, carboxyl, and epoxy. These functions impose a hydrophilic character to GO; as a consequence, the interaction between layers is weaker compared to graphene, making GO an easily exfoliated material. GO structure depends principally on the purification methods (Singh et al., 2016). Compared to graphene, the GO structure is still ambiguous; thus, several structural models have been proposed to date (Dreyer et al., 2010; Sun, 2019). The graphene oxide can be obtained by the popular Hummer's method (Hummers and Offeman, 1958), which, until the date, has been subjected to multiple modifications and improvements (Shamaila et al., 2016). The original method proposes the oxidation of graphite powder by $\mathrm{KMnO}_{4}$ and $\mathrm{NaNO}_{3}$ in $\mathrm{H}_{2} \mathrm{SO}_{4}$ (Hummers and Offeman, 1958). Differences with other modified methods are principally on the type and toxicity of the oxidant reagents, and the quality of the obtained product (Lim et al., 2018).

A fascinating characteristic raised from the physical and chemical properties of graphene materials is the possibility to perform chemical functionalizations mainly to modify its reactivity yielding a large variety of graphene-based materials (GBMs). Thus, they can be currently used in several applications (Bottari et al., 2017; Mohan et al., 2018). Covalent or noncovalent pathways can functionalize GBMs. Non-covalent functionalization involves first the rupture of the van der Waals forces that stake together with the graphene layers with subsequent formation of non-covalent binding with the substrate by $\pi-\pi, \pi$-cation, and van der Waals interactions. For that, mechanical liquid exfoliation assisted by ultrasonication is used to overcome these forces; water, organic solvents, ionic liquids, surfactants, mixtures are employed to disperse, and stabilize the graphene sheets in the exfoliation process. For example, noncovalent functionalization can be obtained by forming a stable dispersion of graphene sheets in polymers (ionic, non-ionic, and polysaccharides), water solutions, and organic solvents as polyvinyl alcohol, chitosan, and alginate. They can be employed to obtain graphene aerogels and hydrogels (Dreyer et al., 2010; Bottari et al., 2017).

On the other hand, the covalent functionalization of graphene (G) yields a low substitution degree due to their stable carbon conjugation. However, covalent functionalization can be done by taking advantage of the oxygenated reactive groups of the graphene oxide (GO) sheets. Therefore, in the same way as the chemical reduction of graphene oxide, the hydroxyl, carboxyl, 


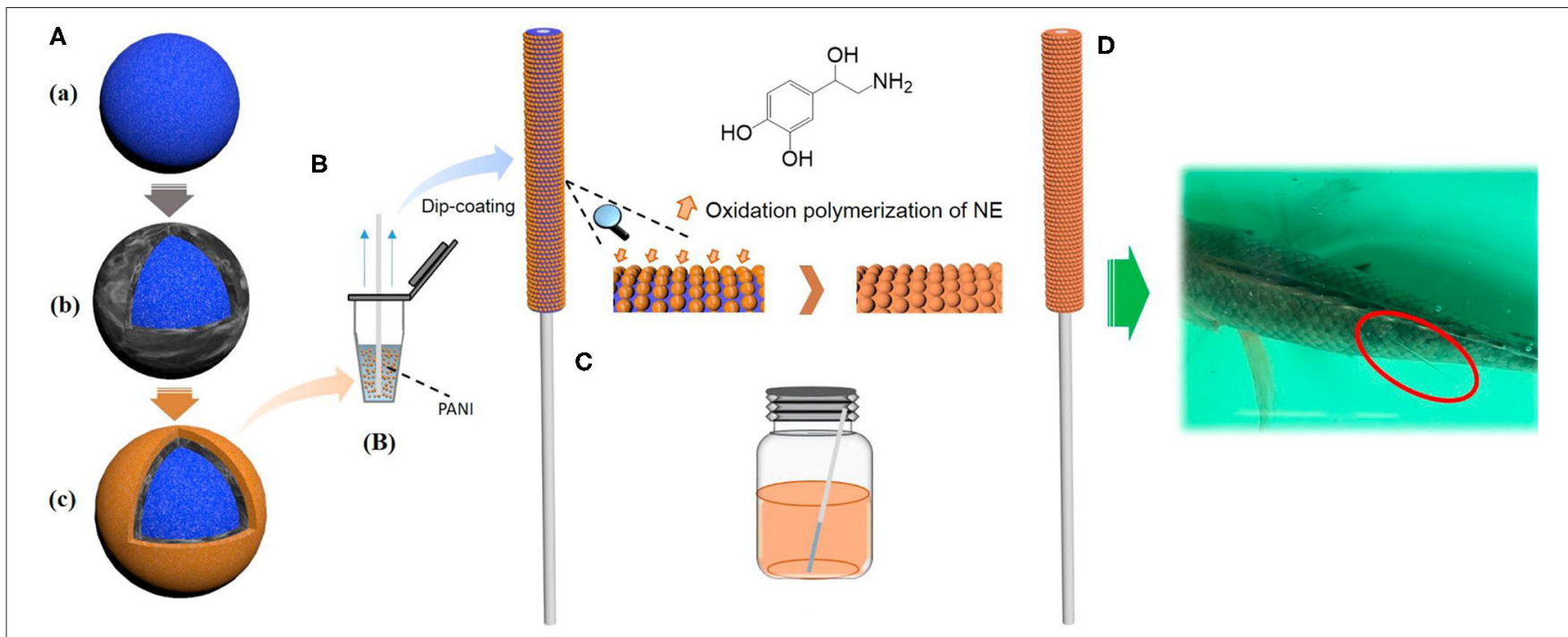

FIGURE 3 | Preparation and application scheme of C18@GO@PDDA SPME fiber. (A) Preparation of the particles (a. C18, b. C18@GO, and c. C18@GO@PDDA). (B) A home-made coated PANI fiber by the dip-coating method. (C) Bioinspired modification by the NE oxidation polymerization. (D) In vivo sampling in fish dorsal-epaxial muscle with the fiber. Reprinted with permission from Qiu et al. (2016), copyright 2016, American Chemical Society.

and epoxy groups can be covalently replaced by other functional groups. The GO surface modification with aliphatic amines to form an amide bond is one of the most common strategies (Dreyer et al., 2010). Undoubtedly, the derivatization of graphene materials improves their electrical, thermal, and mechanical properties as well as their dispersibility (Mohan et al., 2018). Some reasons for the use of functionalized graphene materials as sorbents in sample preparation include: (i) they present improved sorption capacity and recoveries; (ii) easy attachment of graphene onto surfaces to be reusable, and preventing sorbent losses; (iii) avoid the agglomeration of the graphene sheets; and (iv) favored sorbent isolation from the sample (Wang et al., 2014; Ye and Shi, 2015; Chen X. et al., 2016; González-Sálamo et al., 2016).

Considering the increasing use of GBMs in sample preparation techniques, the most representative and used materials in this arena are discussed in the following sections.

\section{ANCHORED GRAPHENE-BASED MATERIALS}

\section{Alkyl and Aril Groups}

Octadecylsilica particles (for short C18 or ODS) are by far the most commonly used sorbent in solid-phase extraction (SPE) and chromatographic separations. Apart from the conventional C8/C18 reversed phases, today mixed-mode polymeric sorbents are widely used in SPE because they present interactions with several compounds and better performance compared to the conventional ones, and they are also commercially available (Fontanals et al., 2020). Alkyl groups, in general, are commonly used to derivatize sorbents, including GO sheets, to modify their fundamental properties. As a consequence, C18 has also been employed to functionalize GO-based sorbents owing to the high surface area of the GO sheets. Their functionalization with octadecylsilane increases the surface load with C18 groups compared to silica particles (Liang et al., 2012; Xu et al., 2012). Subsequently, the extraction capacity is improved, and hydrophobic interactions increased. Therefore, being applied as a sorbet in reverse-phase, they show an improved extraction efficiency for the extraction of alkanes and PAHs, for instance (Xu et al., 2012). Recently, Qui et al. prepared a solidphase microextraction (SPME) fiber with C18 particles $(3.5 \mu \mathrm{m})$ coated with GO and poly(diallyl dimethylammonium chloride) (PDDA)-C18@GO@PDDA as shown in Figures 3A,B. Then, the surface of the fiber was modified by oxidative polymerization by polynorepinephrine ( $\mathrm{pNE}$ ) (Figure 3C), which plays the role of a bio-interface, compatible with in-vivo sampling (Figure 3D). The prepared SPME fibers showed higher efficiency than commercially available ones such as polydimethylsiloxane (PDMS) and polyacrylate (PA) for the monitoring of acidic drugs in fish samples. Additionally, the fiber exhibited excellent stability, sensitivity, and resistance for in-vivo matrices, showing potential for pharmacokinetics applications (Qiu et al., 2016). In another study, the same fiber type was successfully employed to analyze salicylic acid traces in plants in-vivo (Fang et al., 2018).

Although functionalization of GO occupies or replaces part of their original active sites, the sorption capacity of modified-GO materials can be lower or higher compared to GO, which mainly depends on the composite type formed and their specific interaction with the analytes. Even so, GBMs show superior sorptive properties compared to conventional sorbents (e.g., C18), which allows the use of graphene sorbents in small quantities (<100 mg) (Sitko et al., 2013). In this way, $\mathrm{Ma}$ et al. functionalized graphene oxide (GO) sheets with different amine-alkyl chains to obtain amine-rGO sorbents via 
solvothermal synthesis. The sorption capacity of the different alkyl-amine-rGO materials was evaluated for the extraction of catechins and caffeine. Results showed that tributylaminerGO has the highest sorption capacity $\left(203.7 \mathrm{mg} \mathrm{g}^{-1}\right)$ for catechins being 11 times higher compared to GO sheets $(18.7 \mathrm{mg}$ $\mathrm{g}^{-1}$ ) and other rGO-amino groups (ammonia, ethylenediamine, n-butylamine, tert-butylamine, dodecyl amine, and octadecyl amine). Hence, tributylamine-rGO was employed as a sorbent in a modified QuEChERS (quick, easy, cheap, effective, rugged, and safe) method achieving a higher clean-up performance compared to traditional sorbents as PSA, C18, and graphitized carbon black (GCB), regularly used in QuERChERS (Ma et al., 2018). A similar comparison was performed by Fumes et al., which employed aminopropyl silica and PSA particles coated by graphene sheets. The extraction performance of the GO-coated particles, used as a sorbent in microextraction by packed sorbent (MEPS) method, were compared with conventional sorbents (C18, strata-X, PSA, amino silica) for the extraction of parabens in wastewater. Aminopropyl silica coated with GO (SiGO) and $\mathrm{G}(\mathrm{SiG})$ showed an improved extraction performance compared to conventional sorbents (Fumes and Lanças, 2017). Likewise, a recent work performed by the same research group showed improvements in the extraction capability of aminopropyl silicaGO particles when they are functionalized with $\mathrm{C} 18$ and further end-capped. The authors achieved low LODs and LOQs in a complex matrix (coffee samples) by using these particles in a packed in-tube SPME device (Mejía-Carmona and Lanças, 2020). Other interesting graphene-based applications carried out by the Lança's research group also includes tetracyclines' analysis in milk samples (Vasconcelos Soares Maciel et al., 2018) and the determination of triazines in environmental water samples (De Toffoli et al., 2018).

Several additional complex alkyl and aryl compounds have been used to functionalize GO. For example, Nurerk et al. synthesized a hybrid sorbent based on calix[4]arenefunctionalized graphene oxide/polydopamine-coated cellulose acetate fiber (calix[4]arene-GO/PDA-CFs) for the extraction of aflatoxins in corn samples. Calix[4]arene is a macrocyclic molecule of four phenol units bonded by methylene bridges, which can favor the extraction of aflatoxins by H-bonding, hydrophobic, and $\pi-\pi$ interactions. The recoveries of aflatoxins (AFs) obtained employing cellulose acetate CFs (35-41\%), polydopamine coated CFs (PDA-CFs) (45-55\%), calix[4]areneGO-CFs (60-72\%), GO/PDA-CFs (63-82\%), and calix[4]areneGO/PDA-CFs (86-94\%) as SPE sorbents showed that together calix[4]arene and GO increased the efficiency of the sorbent phase (Nurerk et al., 2018). Recently, Zhou et al. synthesized a graphene oxide framework (GOF), a 3D nanoporous material, as coating sorbent for stir bar sorptive extraction (SBSE). Graphene oxide was covalently interconnected with a 1,4phenylene diisocyanate (PPDI) to obtain three-dimensional GOF, which was immobilized onto the surface of stainlesssteel wire (SSW) using polydopamine. The stir bar was applied successfully for the extraction of Sudan dyes in lake water and fruit juice (Zhou J. et al., 2019). Other recently published papers on alkyl and aryl modified graphene materials are shown in Table 1.

\section{Cyclodextrins}

Other emergent graphene-based materials for sample preparation are those combined with cyclodextrins (CD), which are cyclic oligosaccharides formed by starch enzymatic degradation, and are linked by several $\alpha-1,4-$ anhydroglucopyranose. In nature, they are made up of 6 , 7 , or 8 glucose units and categorized as $\alpha, \beta$, and $\gamma$-CD, respectively. CDs have cone shapes with a hydrophobic cavity and a hydrophilic external surface. This specific structure allows them to form inclusion complexes with specific molecules such as polyphenolics compounds through hydrogen bonding, hydrophobic, and Van der Waals interactions (Pinho et al., 2014; Zhu et al., 2016). Reactive OH groups can also be replaced to modify their solubility, improve inclusion ability, or induce desired properties as functionalization for immobilization on a solid support. Consequently, more than $100 \mathrm{CDs}$ are commercially available, and more than 1,500 derivatives have been synthesized for different purposes (Szejtli, 2004; Gentili, 2020).

The reliable recognition capacity of phenolic compounds, due to the excellent size match, becomes common to find works reporting a combination between graphene and cyclodextrins used as electrochemical detectors (Wang C. et al., 2016), electrocatalytic detector (Pham et al., 2016), and electrocatalytic material, for instance (Ran et al., 2017). Thus, there are many different strategies available in the literature to synthesize GBMs functionalized by cyclodextrins. GO functionalization with $\mathrm{CD}$ can be very simple, as reported by Cao et al. (2019). They prepared a suspension containing a graphene-based material and $\beta$-cyclodextrin, with it subsequently stirred under a heated water bath at a temperature of $60^{\circ} \mathrm{C}$ for $4 \mathrm{~h}$. In this case, the resulting material was GO; if it is necessary to reduce graphene oxide to graphene, it can be done using hydrazine (Pham et al., 2016; Tan and $\mathrm{Hu}, 2017)$. As an example, modifications in the synthesis route can be made with (3-aminopropyl)triethoxysilane (APTES) to support an amino group to both graphene oxide nanosheets or cyclodextrins walls (Deng et al., 2017). This procedure results in an amido bonding between epoxy and - $\mathrm{COOH}$ groups of $\mathrm{GO}$ and $-\mathrm{NH}_{2}$ from the APTES. Figure 4 shows a scheme to exemplify the most common bond between GO and cyclodextrin, and how it is expected to be the structure of the graphene-based material functionalized by cyclodextrin.

The combination of graphene and cyclodextrins properties becomes the resulting material attractive to be employed in sample preparation techniques. An interesting application was carried out by Deng et al. The novel $\beta$-CD-GO-coated SPME fiber was prepared using a sol-gel technique and immobilizing onto a pre-functionalized stainless steel wire (Deng et al., 2017). They applied this material as a sorbent in a headspace technique (HS-SPME), aiming to extract organophosphate flame retardants in water samples to be analyzed by gas chromatography with nitrogen phosphorus detector (NPD). The method showed functional recovery $(82.1-116.9 \%)$, linear range with correlation coefficients $(R)$ ranging from 0.9955 to 0.9998 . The LODs and LOQs for the nine analytes ranged from 1.1-60.4 to $2.7-170.5$ ng $\mathrm{L}^{-1}$, respectively; RSD was $2.2-9.6 \%$, and enrichment factors obtained from 22.5 to 1307.5 . This high enrichment 
TABLE 1 | Recent applications (2015-2020) of alkyl and aryl functionalized graphene-based materials in sample preparation.

\begin{tabular}{|c|c|c|c|c|c|c|}
\hline Sorbent & Analytes & Matrix & $\begin{array}{l}\text { Sample } \\
\text { preparation }\end{array}$ & Analysis & LOD & References \\
\hline $\begin{array}{l}\text { Diallyl dimethyl ammonium } \\
\text { chloride-assembled GO-coated C18 } \\
\text { (C18@GO@PDDA) }\end{array}$ & $\begin{array}{l}\text { Salicylic acid } \\
\text { and derivates }\end{array}$ & $\begin{array}{l}\text { Aloe plants } \\
\text { (in-vivo } \\
\text { sampling) }\end{array}$ & SPME fiber & HPLC-DAD & $1.8-2.8 \mu \mathrm{g} \mathrm{g}^{-1}$ & Fang et al., 2018 \\
\hline $\begin{array}{l}\text { Aminopropyl silica coated GO- } \\
\text { functionalized } \\
\text { Octadecylsilane/end-capped } \\
\text { (SiGOC18ecap) }\end{array}$ & Xanthines & Coffee & In-tube SPME & HPLC- MS/MS & $0.1-0.2 \mu \mathrm{g} \mathrm{L}^{-1}$ & $\begin{array}{l}\text { Mejía-Carmona } \\
\text { and Lanças, } 2020\end{array}$ \\
\hline Graphene derivatized silica & Fluoroquinolones & Water & SPE & HPLC-FLD & $2 \mathrm{ng} \mathrm{L}^{-1}$ & $\begin{array}{l}\text { Speltini et al., } \\
2015\end{array}$ \\
\hline $\begin{array}{l}\text { Guanidyl-functionalized GO-grafted } \\
\text { silica (Guanidyl@GO@sil) }\end{array}$ & Herbicides & $\begin{array}{l}\text { Lycium } \\
\text { barbarum }\end{array}$ & SPE & HPLC-UV & $0.5-2.0 \mu \mathrm{g} \mathrm{L}^{-1}$ & Hou et al., 2018b \\
\hline $\begin{array}{l}\text { Polypyrrole-coated GO and C18 } \\
\text { incorporated in chitosan cryogel } \\
\text { (PPY/GOx/C18/CS) }\end{array}$ & $\begin{array}{l}\text { Carbamate } \\
\text { pesticides }\end{array}$ & Fruit juices & SPE & HPLC-UV & $0.5-2.0 \mu \mathrm{g} \mathrm{L}-1$ & $\begin{array}{l}\text { Klongklaew et al., } \\
2018\end{array}$ \\
\hline Alkyl-NH ${ }_{2} / \mathrm{rGO}$ & Pesticides & Tea & $\begin{array}{l}\text { Modified } \\
\text { QuEChERS }\end{array}$ & $\begin{array}{l}\text { GC-MS/MS } \\
\text { UHPLC-MS/MS }\end{array}$ & $\begin{array}{l}0.33-9.26 \mu \mathrm{g} \\
\mathrm{kg}^{-1}\end{array}$ & Ma et al., 2018 \\
\hline $\begin{array}{l}\text { Calix[4]arene-functionalized } \\
\text { GO/polydopamine-coated cellulose } \\
\text { acetate fiber } \\
\text { (calix[4]arene-GO/PDA-CFs) }\end{array}$ & Aflatoxins & Corn & SPE & HPLC-FLD & $\begin{array}{l}0.01-0.05 \mu \mathrm{g} \\
\mathrm{kg}^{-1}\end{array}$ & Nurerk et al., 2018 \\
\hline $\begin{array}{l}\text { Graphene oxide supported on } \\
\text { aminopropyl silica (Si-GO) }\end{array}$ & Tetracyclins & Bovine milk & MEPS & HPLC-MS/MS & $\begin{array}{l}0.03-0.21 \mu \mathrm{g} \\
\mathrm{L}^{-1}\end{array}$ & $\begin{array}{l}\text { Vasconcelos } \\
\text { Soares Maciel } \\
\text { et al., } 2018\end{array}$ \\
\hline $\begin{array}{l}\text { Graphene oxide supported on } \\
\text { aminopropyl silica (Si-GO) }\end{array}$ & Triazines & Water & In-tube SPME & HPLC-MS/MS & $1.1-2.9 \mathrm{ng} \mathrm{L}^{-1}$ & $\begin{array}{l}\text { De Toffoli et al., } \\
2018\end{array}$ \\
\hline $\begin{array}{l}\text { Graphene-C18 Reinforced Hollow Fiber } \\
\text { (G-C18-HF) }\end{array}$ & Chlorophenols & Honey & HF-LPME & HPLC-UV & $0.5-1.5 \mu \mathrm{g} \mathrm{kg}^{-1}$ & Sun et al., 2014 \\
\hline $\begin{array}{l}\text { Poly(diallyldimethylammoniumchloride) } \\
\text { assembled GO-coated C18 particles } \\
\text { (C18@GO@PDDA) }\end{array}$ & $\begin{array}{l}\text { Acidic } \\
\text { pharmaceuticals }\end{array}$ & $\begin{array}{l}\text { Fish (in-vivo } \\
\text { sampling) }\end{array}$ & SPME fiber & HPLC-MS/MS & $\begin{array}{l}0.13-7.56 \mu \mathrm{g} \\
\mathrm{kg}^{-1}\end{array}$ & Qiu et al., 2016 \\
\hline $\begin{array}{l}\text { Graphene oxide/silica modified with } \\
\text { nitro-substituted tris(indolyl)methane }\end{array}$ & Organic acids & $\begin{array}{l}\text { Honey and } \\
\text { nongfu spring } \\
\text { drink }\end{array}$ & SPE & HPLC-DAD & $0.5-1.0 \mu \mathrm{g} \mathrm{L}-1$ & $\begin{array}{l}\text { Wang N. et al., } \\
2016\end{array}$ \\
\hline $\begin{array}{l}\text { Graphene supported on aminopropyl } \\
\text { silica (Si-G) and primary-secondary } \\
\text { amine (PSA) silica (PSA-G) }\end{array}$ & Parabens & Water & MEPS & UHPLC-MS/MS & $\begin{array}{l}0.06-0.09 \mu \mathrm{g} \\
\mathrm{L}^{-1}\end{array}$ & $\begin{array}{l}\text { Fumes and } \\
\text { Lanças, } 2017\end{array}$ \\
\hline Acrylamide-functionalized graphene & $\begin{array}{l}\text { Monoamine } \\
\text { acidic } \\
\text { metabolites }\end{array}$ & $\begin{array}{l}\text { Urine and } \\
\text { plasma }\end{array}$ & $\mu \mathrm{SPE}$ & HPLC-UV & $\begin{array}{l}0.08-0.25 \mu \mathrm{g} \\
\mathrm{L}^{-1}\end{array}$ & Yang et al., 2015 \\
\hline Tannic acid functionalized graphene & Beryllium & $\begin{array}{l}\text { Wastewater and } \\
\text { street dust }\end{array}$ & d-SPE & $\begin{array}{l}\text { Atomic } \\
\text { absorption }\end{array}$ & $0.84 \mathrm{ng} \mathrm{L}^{-1}$ & Yavuz et al., 2018 \\
\hline $\begin{array}{l}\text { GO framework interconnected by } \\
\text { 1,4-phenylene diisocyanate (PPDI) }\end{array}$ & $\begin{array}{l}\text { Sudan dyes (G, } \\
I, \text { II, and III) }\end{array}$ & $\begin{array}{l}\text { Lake water and } \\
\text { fruit juice }\end{array}$ & SBSE & HPLC-UV & $0.15-0.3 \mu \mathrm{g} \mathrm{L}{ }^{-1}$ & $\begin{array}{l}\text { Zhou J. et al., } \\
2019\end{array}$ \\
\hline
\end{tabular}

factor is attributed to the combined advantages of $\beta$-CD and GO. When compared with the commercial fibers and some published methods, the GO/ $\beta$-CD sol-gel coating fiber showed a higher extraction efficiency, except for those organophosphate flame retardants containing a benzene ring. Similarly, Cao et al. combined the advantages of graphene and cyclodextrins with ionic liquids and ILs (Cao et al., 2019). They synthesized a $\mathrm{VOIm}^{+} \mathrm{AQSO}_{3}^{-}$functionalized $\beta$-cyclodextrin/magnetic graphene oxide material $\left(\mathrm{Fe}_{3} \mathrm{O}_{4} @ \mathrm{SiO}_{2} / \mathrm{GO} / \beta-\mathrm{CD} / \mathrm{IL}\right)$, which was used as a sorbent to extract plant growth regulators from vegetable samples using magnetic solid-phase extraction
(MSPE) followed by UHPLC-MS/MS analysis. This approach showed fast separation, high surface area, high adsorption capability, and environmental friendliness. The comparison between $\mathrm{Fe}_{3} \mathrm{O}_{4} @ \mathrm{SiO}_{2} / \mathrm{GO}, \quad \mathrm{Fe}_{3} \mathrm{O}_{4} @ \mathrm{SiO}_{2} / \mathrm{GO} / \beta-\mathrm{CD}$, and $\mathrm{Fe}_{3} \mathrm{O}_{4} @ \mathrm{SiO}_{2} / \mathrm{GO} / \mathrm{IL}$ showed that $\mathrm{Fe}_{3} \mathrm{O}_{4} @ \mathrm{SiO}_{2} / \mathrm{GO} / \beta-\mathrm{CD} / \mathrm{IL}$ had higher extraction efficiency and selective adsorption capacity.

For food analysis, $\beta$-CD combined with GO were used in the sample preparation during the analysis of organochlorine pesticide residues in honey (Mahpishanian and Sereshti, 2017). The prepared material was applied as a sorbent in vortex-assisted magnetic solid-phase extraction (MSPE) before 


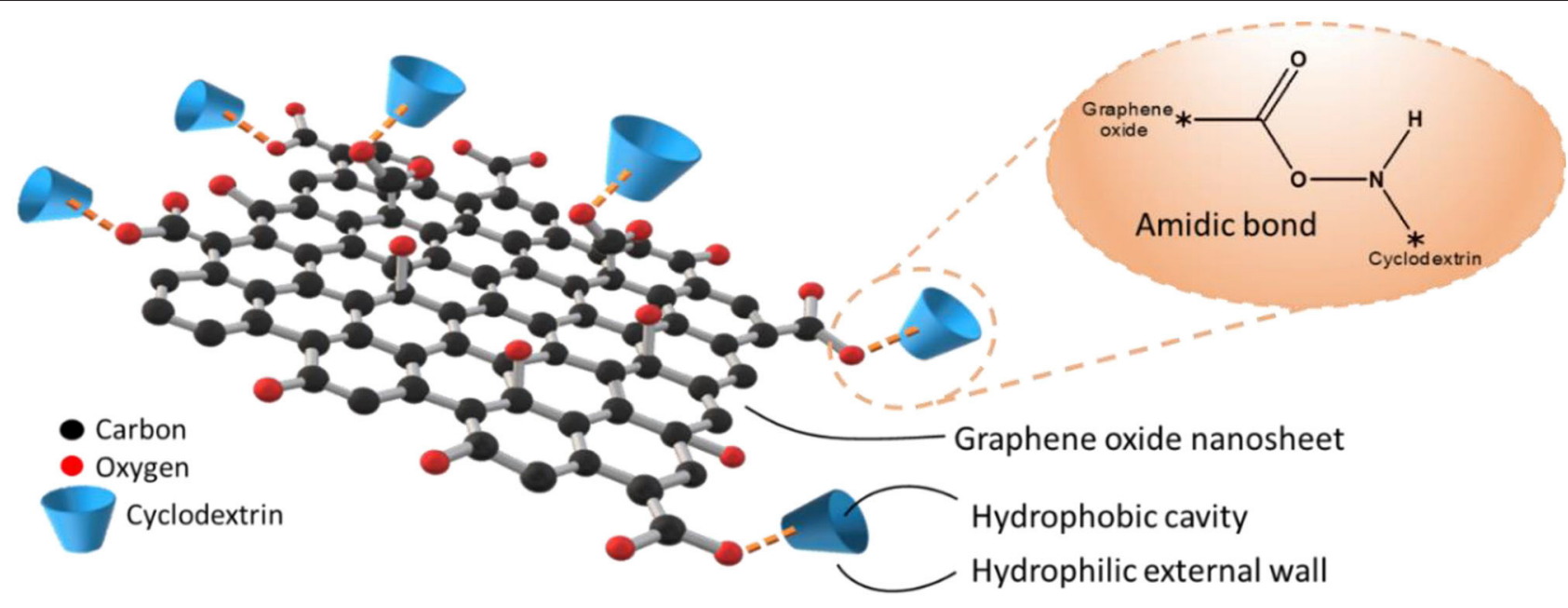

FIGURE 4 | Scheme illustrating a graphene-based sorbent functionalized with cyclodextrins through peptide bonds.

TABLE 2 | Recent applications (2017-2020) of graphene-based materials functionalized by cyclodextrins to sample preparation.

\begin{tabular}{|c|c|c|c|c|c|c|}
\hline Sorbent & Analytes & Matrix & $\begin{array}{l}\text { Sample } \\
\text { preparation }\end{array}$ & Analysis & LOD & References \\
\hline $\mathrm{G}-\mathrm{Fe}_{3} \mathrm{O}_{4}-\beta-\mathrm{CD}$ & Bisphenol-A & Water & MSPE & UV-vis & $\star *$ & $\begin{array}{l}\text { Ragavan and } \\
\text { Rastogi, } 2017\end{array}$ \\
\hline GNS/ $\beta-C D$ & Phenolphthalein & Water & d-SPE & UV-vis & $\star \star$ & Tan and Hu, 2017 \\
\hline $\mathrm{Fe}_{4} \mathrm{O}_{3}-\mathrm{GO}-\beta-\mathrm{CD}$ & $\begin{array}{l}\text { Neonicotinoid } \\
\text { pesticide }\end{array}$ & Water & MSPE & HPLC-MS/MS & $* *$ & Liu G. et al., 2017 \\
\hline$\beta-\mathrm{CD} / \mathrm{MrGO}$ & $\begin{array}{l}\text { Organochlorine } \\
\text { pesticides }\end{array}$ & Honey & MSPE & GC-ECD & $0.52-3.21 \mathrm{ng} \mathrm{kg}^{-1}$ & $\begin{array}{l}\text { Mahpishanian and } \\
\text { Sereshti, } 2017\end{array}$ \\
\hline $\mathrm{GO} / \beta-\mathrm{CD}$ sol-gel coating fiber & $\begin{array}{l}\text { Organophosphate } \\
\text { flame retardants }\end{array}$ & Environmental water & HS-SPME & GC-NPD & $1.1-60.4 \mathrm{ng} \mathrm{L}^{-1}$ & Deng et al., 2017 \\
\hline $\mathrm{Fe}_{3} \mathrm{O}_{4} @ \mathrm{SiO}_{2} / \mathrm{GO} / \beta-\mathrm{CD} / \mathrm{LL}$ & $\begin{array}{l}\text { Plant growth } \\
\text { regulators }\end{array}$ & Vegetables & MSPE & UHPLC-MS/MS & $0.01-0.18 \mu \mathrm{g} \mathrm{kg}^{-1}$ & Cao et al., 2019 \\
\hline
\end{tabular}

${ }^{\star \star}$ Not specified.

gas chromatography-electron capture detection (GC-ECD) analysis. The method was optimized and evaluated, showing linearity ranging from 2 to $10,000 \mathrm{ng} \mathrm{kg}^{-1}$ and $R^{2}>0.9966$, RSDs $<7.8 \%$, LODs from $0.52-3.21 \mathrm{ng} \mathrm{kg}^{-1}$, and LOQ from 1.73$10.72 \mathrm{ng} \mathrm{kg}^{-1}$. For the real samples, the proposed sorbent showed good recoveries in the range of $78.8-116.2 \%$ with RSDs $(n=3)$ below $8.1 \%$.

These works demonstrated that cyclodextrins' functionalized GBMs possess great supramolecular recognition, high extraction efficiency, good recoveries, and enrichment capability. It is noteworthy that in all reported works, the chosen graphenebased material is actually the graphene oxide (GO). This trend is justified by the presence of epoxy and - $\mathrm{COOH}$ groups on the GO surface, favoring the bonding with the CDs. Although some works reported the employment of graphene combined with cyclodextrins as sorbent, these materials were obtained by graphene oxide reduction (Ragavan and Rastogi, 2017; Tan and $\mathrm{Hu}, 2017)$. In this strategy, the reduction stage can be performed before or after the support between graphene-based and CDs. In this way, considering that the oxygenated groups present in the GO structure can improve interaction with molecules of $\beta$ CD (Tan and $\mathrm{Hu}, 2017$ ), it is presumable that the reduction of graphene oxide after $\beta$-CD coupling is the best synthesis route to maximize the amount of cyclodextrin coupled.

To complement this topic, Table 2 presents recently published works using graphene-based materials combined with cyclodextrins for sample preparation. It must be highlighted that all applications employed $\beta$-cyclodextrin. Considering the existence of over 100 commercially available and more than 1,500 derivative materials already described, it is clear that sorbents based on graphene functionalized with cyclodextrins are a broad research field to be still explored. Finally, the GBMs/CD's excellent characteristics for supramolecular recognition, high extraction efficiencies, good recoveries, and enrichment capability should contribute to its widespread development in the coming years. 


\section{Magnetic Materials}

Although graphene and its derivatives are considered to be cutting-edge materials in modern sorbent-based sample preparation (Toffoli et al., 2018; Grajek et al., 2019; Hou et al., 2019), their use can be related to some drawbacks in both bedpacked and dispersive microextraction. Their strong van der Waals interactions may cause irreversible aggregation of the material, causing graphene swelling, which often occurs due to the continuous water/solvent deposition between the graphene nanosheets (Zheng et al., 2017; Iakunkov et al., 2019). For these reasons, columns and microextraction devices packed with GBMs are usually susceptible to clogging and high backpressures. Likewise, for dispersive techniques, graphene nanosheets are well-suspended in solution, creating difficulty for the sorbent recovery, even after filtration and centrifugation (Hou et al., 2019; Li F. et al., 2020).

Within such a context, a modern, and advantageous strategy to overcome those drawbacks is the magnetic solid-phase extraction (MSPE) which is considered an efficient and environmentfriendly sample preparation technique (Šafariková and Šafarik, 1999). MSPE extraction mechanism relies on the use of extraction sorbents supported over magnetic materials (Laura et al., 2019). In general, MSPE is a dispersive technique-thin-films or blocks format are also possible-in which the sorbent collection from the sample bulk is easily performed by application of an external magnetic field (Ibarra et al., 2015; Evrim et al., 2019). The use of graphene-based materials for MSPE not only efficiently eliminates the clogging problems from the packed-dispositive but can also enhance the extraction capacity due to GBMs' properties. Also, MSPE possibly eliminates additional centrifugation and filtration steps (Li et al., 2018). For these reasons, the use and development of magnetic sorbents incorporating GBMs have become a key-point in sample preparation in recent years. Nowadays, this combination has been applied in the MSPE of a wide diversity of organic and inorganic analytes from several complex samples, including the treatment of solid matrices (Feriduni, 2019).

These graphene-based magnetic sorbents are currently obtained by physical or chemical anchoring of the magnetic carries onto the graphene sheets. The most common carries include iron $(\mathrm{Fe})$, cobalt, (Co), and nickel (Ni) oxides, highlighting the magnetite $\left(\mathrm{Fe}_{3} \mathrm{O}_{4}\right)$ and maghemite $\left(\gamma-\mathrm{Fe}_{2} \mathrm{O}_{3}\right)$ as the magnetic nanoparticles (MNPs) more frequently used (Laura et al., 2019). The $\mathrm{Fe}_{3} \mathrm{O}_{4}$ and $\gamma-\mathrm{Fe}_{2} \mathrm{O}_{3}$ have superparamagnetic properties, are easy to prepare, and disperse very well in aqueous solutions. Besides, those are MNPs feasible to be modified and functionalized ( $Y u$ M. et al., 2019). More popular methods for the preparation of $\mathrm{Fe}_{3} \mathrm{O}_{4}$ and $\gamma$-Fe2O3 based magnetic sorbents include chemical co-precipitation, hydrothermal synthesis, sol-gel reactions, solvothermal synthesis, thermal decomposition, microemulsion, and sonochemical approaches (Filik and Avan, 2019).

The most straightforward type of graphene magnetic sorbents is prepared by direct immobilization of the MNPs on the surface of the G. In this context, two synthetic routes can be employed for obtaining them: (i) the chemical co-precipitation and (ii) the hydrothermal synthesis. The chemical co-precipitation is based on the deposition of iron ions over the nanosheets by adding an alkaline solution to an aqueous dispersion of graphene $\mathrm{Fe}^{3+} / \mathrm{Fe}^{2+}$ salts, at elevated temperature and vigorous stirring. For example, this method was employed by Yang et al. to prepare superparamagnetic $\mathrm{GO} / \mathrm{Fe}_{3} \mathrm{O}_{4}$ nanoparticles (Yang et al., 2009). After primary treatment of GO sheets, a dispersion of $\mathrm{GO}, \mathrm{FeCl}_{3}$ was stirred under inert atmosphere by several hours. After that, $\mathrm{Fe}^{3+} / \mathrm{Fe}^{2+}$ ions were coordinated by the carboxylate anions on the $\mathrm{GO}$ sheets, and then $\mathrm{GO} / \mathrm{Fe}_{3} \mathrm{O}_{4}$ nanoparticles were precipitated by the addition of an aqueous $\mathrm{NaOH}$ solution (Figure 5). As $\mathrm{Fe}^{3+}$ shows higher affinity than $\mathrm{Fe}^{2+}$ for carboxylic groups, the ratio of those ions should be controlled-generally, 2:1 is used-and the content of the carboxylic acid groups on the GO sheets needs to be previously determined by acidbase titration (Yang et al., 2009). The chemical co-precipitation method can also be employed to prepare magnetic reduced graphene oxide sorbents $\left(\mathrm{rGO} / \mathrm{Fe}_{3} \mathrm{O}_{4}\right)$. As an example, Chandra et al. prepared an $\mathrm{rGO} / \mathrm{Fe}_{3} \mathrm{O}_{4}$ for arsenic removal from surface water samples (Chandra et al., 2010). In this case, after dispersion and precipitation with ammonia, $\mathrm{GO} / \mathrm{Fe}_{3} \mathrm{O}_{4}$ particles were reduced to $\mathrm{rGO} / \mathrm{Fe}_{3} \mathrm{O}_{4}$ by slowly adding hydrazine hydrate under stirring conditions $90^{\circ} \mathrm{C}$.

An important issue is that the morphology of graphene magnetic sorbents prepared via chemical co-precipitation can be challenging to control. Thus, the resulting magnetic material sometimes presents low absorptivity due to the uneven distribution and agglomeration of the $\mathrm{Fe}_{3} \mathrm{O}_{4}$ particles on the nanosheets. Within such a context, hydrothermal synthesis has been proposed as an alternative to yield sorbents with better $\mathrm{Fe}_{3} \mathrm{O}_{4}$ particles distribution with more $\mathrm{G}$ exposed adsorption sites and then, improved adsorption capacity. This method is based on the reduction of $\mathrm{Fe}^{3+}$ and GO in sodium acetate and polyethyleneglycol in an autoclave at elevated temperature ( $\mathrm{Li}$ et al., 2018). In this way, $\mathrm{Wu}$ and cookers prepared $\mathrm{rGO} / \mathrm{Fe}_{3} \mathrm{O}_{4}$ particles (Wu et al., 2013), sonicating GO first in ethylene glycol, and then in the presence of $\mathrm{FeCl}_{3}$. After complete dispersion, the obtained clear solution was spiked with sodium acetate, and the mixture was sealed in a Teflon-lined stainless-steel autoclave and maintained at $200^{\circ} \mathrm{C}$ for $8 \mathrm{~h}$. The authors reported regular morphology particles.

Also, more reproducible, stable, and versatile graphene magnetic sorbents can be prepared from silica-coated magnetite particles $\left(\mathrm{Fe}_{3} \mathrm{O}_{4} @ \mathrm{SiO} 2\right)$. In this case, before graphene anchoring, $\mathrm{Fe}_{3} \mathrm{O}_{4}$ particles are modified with a silane coupling agent, consisting of tetraethyl orthosilicate (TEOS) and (3-aminopropyl) triethoxysilane (APTES) (Li et al., 2018). Sequentially, the graphene can be coupled to the particles by physical adsorption or by covalent bonding. Luo et al. prepared $\mathrm{Fe}_{3} \mathrm{O}_{4} @ \mathrm{SiO}_{2} / \mathrm{G}$ particles for extraction of sulfonamides from water samples, by physical immobilization of graphene nanosheets on silica-coated magnetite (Luo et al., 2011b). The procedure obtained by pure dispersion under sonication for several hours renders particles not stable enough to continue reusing. Therefore, the chemical bonding of the graphene to the silanol groups is the preferred synthetic method. Amino groups are introduced on the surface of the Fe3O4@SiO2 particles and GO, anchored via an amidation 


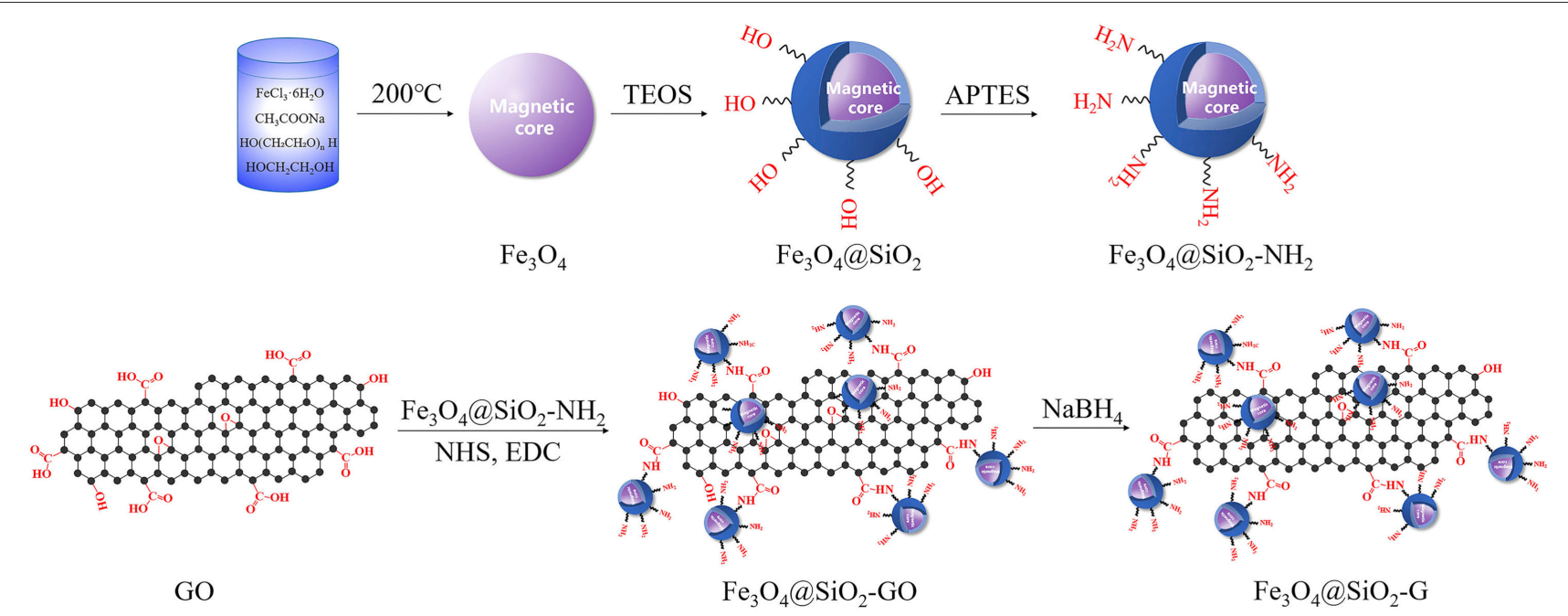

TEOS: tetraethyl orthosilicate; APTES: (3-aminopropyl) triethoxysilane; NHS: $n$-hydroxysuccinimide; EDC: 1-(3-dimethylaminopropyl)-3-ethylcarbodiimide hydrochloride

FIGURE 5 | Schematic representation of GO loaded with Fe304 nanoparticles. Reprinted with permission from Yang et al. (2009), copyright 2009, Royal Society of Chemistry.

reaction with the aid of cross-linking agents such as 1-(3dimethyl aminopropyl)-3-ethyl carbodiimide hydrochloride (EDC) and -hydroxysuccinimide (NHS). This process is schematically represented in Figure 6 (Li et al., 2018). For example, Zhang et al. prepared $\mathrm{Fe}_{3} \mathrm{O}_{4} @ \mathrm{SiO}_{2} / \mathrm{GO}$ particles by mixing $\mathrm{Fe}_{3} \mathrm{O}_{4} @ \mathrm{SiO}_{2}$ and 3-aminopropyltriethoxysilane in isopropanol, under $\mathrm{N}_{2}$ atmosphere at $70^{\circ} \mathrm{C}$, followed by addition of a GO solution containing NHS and EDC, stirring overnight (Zhang et al., 2014). Like $\mathrm{Fe}_{3} \mathrm{O}_{4} / \mathrm{rGO}$ composites, $\mathrm{Fe}_{3} \mathrm{O}_{4} @ \mathrm{SiO}_{2} / \mathrm{rGO}$ particles can be obtained by the posterior reduction of $\mathrm{GO}$ with hydrazine.

The adsorption capacity of these magnetic particles is mostly based on the hydrophobic interactions of the honeycomb-like lattice into the carbon atoms. Consequently, bare graphene magnetic particles are not suitable MSPE sorbents for polar or ionic compounds. The main advantage of the $\mathrm{Fe}_{3} \mathrm{O}_{4} @ \mathrm{SiO}_{2} / \mathrm{G}$ particles is the possibility to covalently bond additional functional moieties, which improve the adsorption capacity, selectivity, and applicability of them. In this manner, $\mathrm{Fe}_{3} \mathrm{O}_{4} @ \mathrm{SiO}_{2} / \mathrm{G}$ have been covalently functionalized with ionic surfactants, ionic liquids (ILs), deep eutectic solvents, boronate affinity materials (BAM), supramolecules (crown ethers, cyclodextrins, calixarenes, cucurbiturils, and pillararenes), aptamers, polymers, and metal-organic frameworks (MOFs). For those magnetic GBMs, their preparation and applications were recently comprehensively reviewed by $\mathrm{Li}$ et al. They provided a summary of the state of the art of them, highlighting application as MSPE sorbents of organic compounds, biomolecules, and metal ions (Li et al., 2018). For this reason, herein, we provide an updated overview of the reported magnetic graphene sorbents between 2019 and 2020, and their applications in the determination of small organic molecules by chromatographic analysis.
In this context, magnetic graphene sorbents have found spread applications in the extraction of biomolecules organic compounds and metal ions. An assessment in the Scopus database, using the keywords "graphene" and "magnetic solidphase extraction," yield 248 results from 2010. Among them, 26 correspond to review papers and the rest to research papers mainly dedicated to describing the application of magnetic graphene sorbent in different areas of the analytical chemistry. As mentioned previously, Li et al. recently published a summary of the applications of graphene-based MSPE. In Table 3, we provide a summary of the magnetic graphene sorbent applications published from 2019 to date. It is noteworthy that a vast number of researchers using graphene-derived magnetic materials focus their efforts in areas as environmental surveillance and food security applications. This includes a wide diversity of analytes such as drug residues, pesticides, hormones, food additives, and active plant ingredients.

\section{Molecularly-Imprinted Polymers}

Another group of materials explored for sample preparation involves the molecularly-imprinted polymers (MIPs) combined with GBMs. In this context, MIPs are prepared from a template (mold) which behaves structurally similarly as the target analytes, to achieve a selective interaction through a templatecomplementary binding site (Pan et al., 2018). These materials are traditionally prepared by copolymerization of the complex formed between the template and a functional monomer. This can occur through either covalent (hydrogen bonds) or noncovalent bonds (ionic and hydrophobic interactions) with a cross-linking agent in the presence of a suitable porogenic solvent (Zhou T. et al., 2019). After that, the molecular template is eliminated, resulting in a rigid three-dimensional cavity selective to the target analytes. As an example, Figure 7 depicts the 


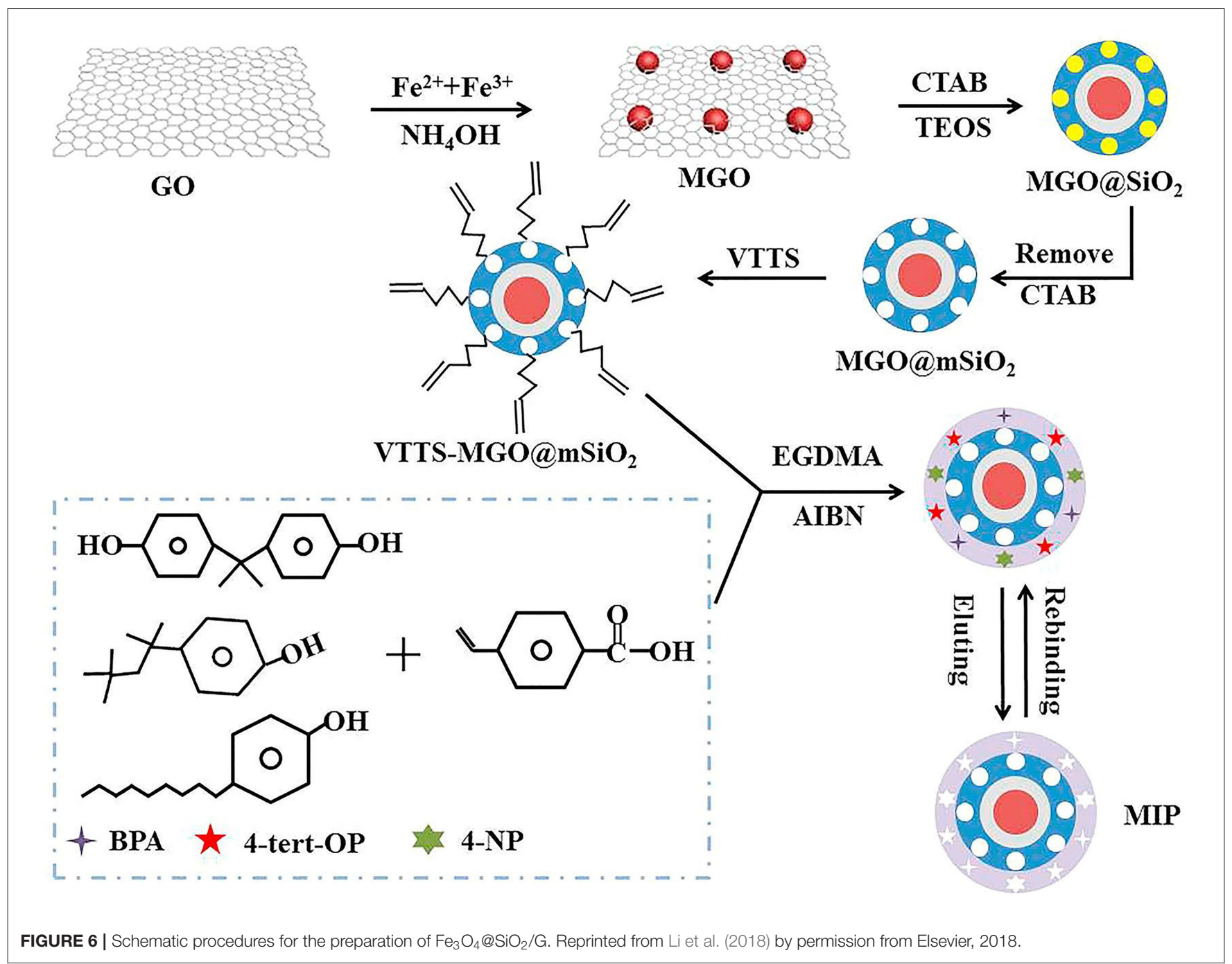

synthesis steps employed by Xie et al. (2019). The authors selected 4-vinylbenzoic acid as a functional monomer to prepare the template taking advantage of the presence of the carboxyl ring and benzene, which can bind to BPA, 4- tert-OP, and 4 -NP through hydrogen bonds and $\pi-\pi$ interactions in the polymerization process.

Due to this high selectivity and relatively easy preparation, these materials have been widely used for molecular recognition and separation in different fields (sensors, drug delivery, protein recognition, and chromatography). In this section, their application in the field of sample preparation combined with GBMs is covered, highlighting preparation strategies of aqueousrecognition MIPs cleverly to achieve such functionalization (Zhou T. et al., 2019). For example, Luo et al. (2017) synthesized boronic acid-functionalized with graphene oxide, with a subsequent immobilization of ovalbumin as MIP-template, to obtain a high-selective sorbent, namely GO-APBA/MIPs. This strategy was chosen to overcome such difficulties related to specific recognition and separation of glycoproteins in complex biological samples. A comparison between the resulting material
(GO-APBA/MIPs) and a bare GO-MIPs, without insertion of boronic acid, showed more extraction performance for the hybrid obtained sorbent. In this way, the outstanding recognition capacity by linking boronic acid and MIP cavities together with a high surface area of GO can represent a promising strategy to produce high performative sorbent material for biological glycoproteins.

Another interesting example was reported by Cheng et al. (2017), consisting of a more straightforward strategy using GO combined with MIP to extract and efficiently pre-concentrate bis(2-ethylhexyl) phthalate (DEHP) in environmental water samples. Contrary to the prior study (Luo et al., 2017), considering the smaller complexity of the target compound and water samples, the employment of only GO-MIP was already enough to achieve excellent extraction performance. In this case, dispersive solid-phase microextraction combined with HPLC-UV reported enrichment factors of more than 100-fold compared to the directly injected extract, highlighting this simple GO-MIP as a suitable sorbent in such cases. 
TABLE 3 | Recent applications (2019-2020) of graphene-based MSPE to the determination of organic compound by chromatography and mass spectrometry.

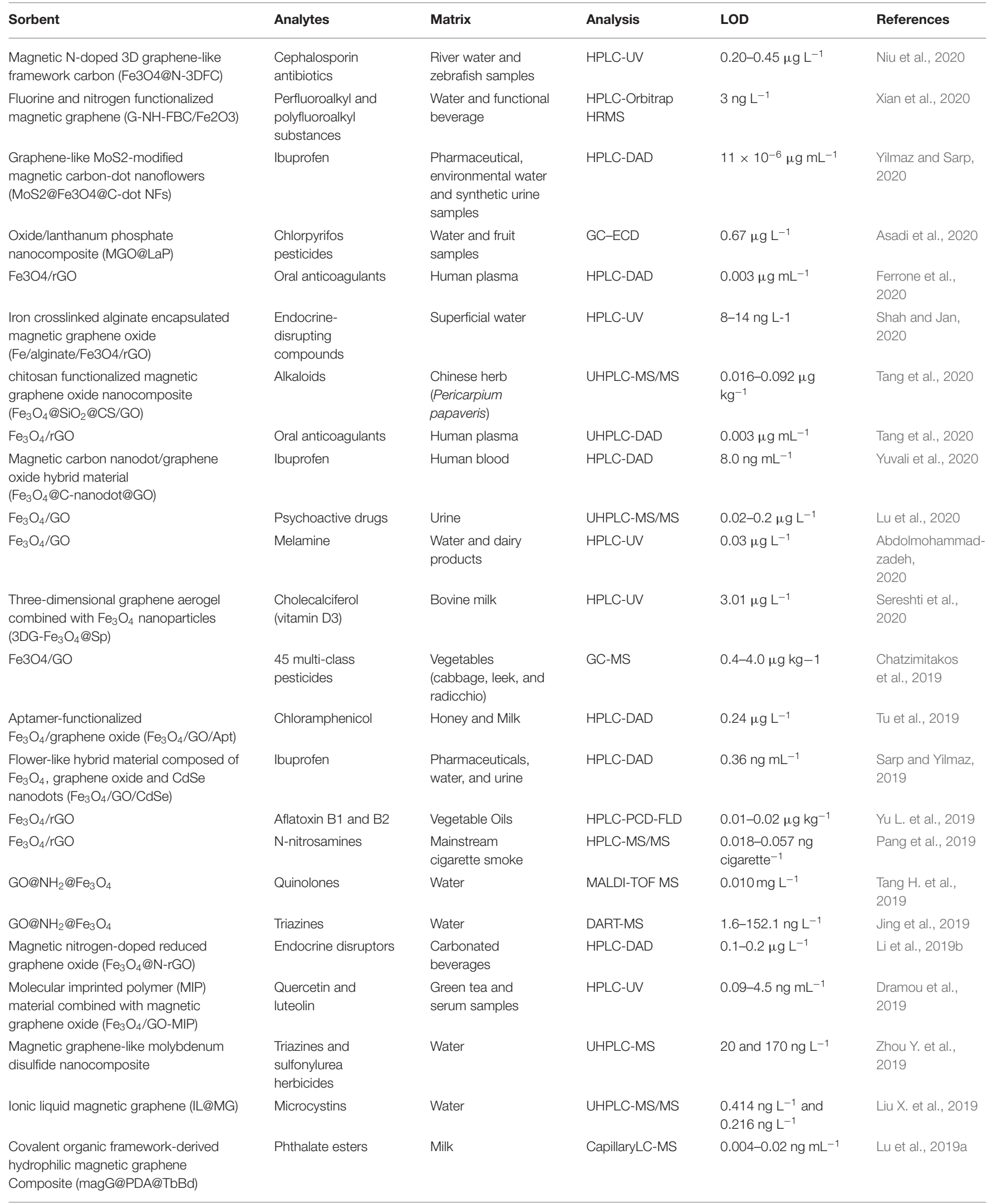


TABLE 3 | Continued

\begin{tabular}{|c|c|c|c|c|c|}
\hline Sorbent & Analytes & Matrix & Analysis & LOD & References \\
\hline $\begin{array}{l}\text { Curcumin loaded magnetic graphene } \\
\text { oxide }\end{array}$ & Parabens & $\begin{array}{l}\text { Toothpaste and } \\
\text { mouthwash }\end{array}$ & HPLC-DAD & $0.4-1.0 \mathrm{ng} \mathrm{mL}^{-1}$ & $\begin{array}{l}\text { Razavi and Es, } \\
2019\end{array}$ \\
\hline $\mathrm{Fe}_{3} \mathrm{O}_{4} / \mathrm{rGO}$ & $\begin{array}{l}\text { Non-steroidal } \\
\text { Anti-inflammatory } \\
\text { Drugs }\end{array}$ & Animal food & HPLC-MS/MS & $0.1-0.5 \mu \mathrm{g} \mathrm{kg}^{-1}$ & Wang et al., 2019 \\
\hline $\mathrm{Fe}_{3} \mathrm{O}_{4} / \mathrm{rGO}$ & $\begin{array}{l}\text { Phenolic } \\
\text { compounds }\end{array}$ & Oil seeds & LC-MS/MS & $0.02-90.00 \mu \mathrm{g} \mathrm{kg}^{-1}$ & Lang et al., 2019 \\
\hline $\mathrm{Fe}_{3} \mathrm{O}_{4} / \mathrm{rGO}$ & Pesticides & Water & HPLC-UV & $0.2-1.6 \mathrm{ng} \mathrm{mL}^{-1}$ & Madej et al., 2019 \\
\hline $\begin{array}{l}\text { Three-dimensional hierarchical } \\
\text { frameworks based on molybdenum } \\
\text { disulfide-graphene oxide-supported } \\
\text { magnetic nanoparticles } \\
\left(\mathrm{Fe}_{3} \mathrm{O}_{4} / \mathrm{GO} / \mathrm{MoS}_{2}\right)\end{array}$ & $\begin{array}{l}\text { Fluoroquinolone } \\
\text { antibiotics }\end{array}$ & Water & HPLC-UV & $0.25-0.50 \mathrm{ng} \mathrm{mL}^{-1}$ & Xiao et al., 2019 \\
\hline $\begin{array}{l}\text { Magnetic nanoparticles/graphene oxide } \\
\left(\mathrm{TPN} / \mathrm{Fe}_{3} \mathrm{O}_{4} \mathrm{NPS} / \mathrm{GO}\right) \text { nanocomposite }\end{array}$ & Pesticides & Water & HPLC-UV & $0.17-1.7 \mu g \mathrm{~L}^{-1}$ & Moradi et al., 2019 \\
\hline $\begin{array}{l}\text { Silver-modified } \mathrm{Fe}_{3} \mathrm{O}_{4} / \text { graphene } \\
\text { nanocomposite }\left(\mathrm{Ag} @ \mathrm{Fe}_{3} \mathrm{O}_{4} @ \mathrm{G}\right)\end{array}$ & Aromatic amines & Water & HPLC-UV & $0.10-0.20 \mu \mathrm{g} \mathrm{L}^{-1}$ & Alasl et al., 2019 \\
\hline $\mathrm{Fe}_{3} \mathrm{O}_{4} / \mathrm{GO}$ & Chlorophenols & Sewage water & GC-ECD & $3.0-28.4 \mathrm{ng} L^{-1}$ & $\begin{array}{l}\text { Esfandiarnejad } \\
\text { and Sereshti, } 2019\end{array}$ \\
\hline $\begin{array}{l}\text { Ternary nano-composite, } \\
\text { magnetite/reduced graphene } \\
\text { oxide/silver }\left(\mathrm{Fe}_{3} \mathrm{O}_{4} / \mathrm{rGO} / \mathrm{Ag}\right)\end{array}$ & $\begin{array}{l}\text { Morphine and } \\
\text { codeine }\end{array}$ & Blood and urine & HPLC-UV-VIs & $1.8-2.1 \mathrm{ng} \mathrm{L}^{-1}$ & $\begin{array}{l}\text { Abdolmohammad- } \\
\text { zadeh et al., } \\
2019\end{array}$ \\
\hline $\begin{array}{l}\text { Magnetic amino-functionalized zinc } \\
\text { metal-organic framework based on a } \\
\text { magnetic graphene oxide composite } \\
\left(\mathrm{M}-\mathrm{IRMOF} / \mathrm{Fe}_{3} \mathrm{O}_{4} / \mathrm{GO}\right)\end{array}$ & $\begin{array}{l}\text { Heterocyclic } \\
\text { fungicides }\end{array}$ & Lettuce & HPLC-MS/MS & $0.21-1.0 \mu \mathrm{g} \mathrm{L}^{-1}$ & Liu G. et al., 2019 \\
\hline $\mathrm{Fe}_{3} \mathrm{O}_{4} / \mathrm{rGO}$ & Chiral pesticides & $\begin{array}{l}\text { Cucumber, tomato, } \\
\text { cabbage, grape, } \\
\text { mulberry, apple, and } \\
\text { pear }\end{array}$ & $\begin{array}{l}\text { Chiral } \\
\text { HPLC-MS/MS }\end{array}$ & $0.02-10.0 \mu g^{-1}$ & Zhao et al., 2019 \\
\hline $\begin{array}{l}\text { Reduced graphene oxide-carbon } \\
\text { nanotubes composite } \\
\left.\text { ( } \mathrm{Fe}_{3} \mathrm{O}_{4} / \mathrm{rGO}-\mathrm{CNTS}\right)\end{array}$ & Sulfonamides & Milk & HPLC-UV & $0.35-1.32 \mu \mathrm{g} \mathrm{L}{ }^{-1}$ & Feng et al., 2019 \\
\hline $\begin{array}{l}\text { Magnetic graphene oxide/multiwalled } \\
\text { carbon nanotube core-shell } \\
\left(\mathrm{GO} / \mathrm{MWCNT} / \mathrm{Fe}_{3} \mathrm{O}_{4} / \mathrm{SiO}_{2}\right)\end{array}$ & $\begin{array}{l}\text { Paracetamol and } \\
\text { caffeine }\end{array}$ & $\begin{array}{l}\text { Synthetic urine and } \\
\text { wastewater }\end{array}$ & HPLC-UV & $0.48-3.32 \mathrm{ng} \mathrm{mL}^{-1}$ & $\begin{array}{l}\text { Ibrahim et al., } \\
2019\end{array}$ \\
\hline $\begin{array}{l}\text { Magnetized graphene oxide } \\
\text { functionalized with hydrophilic phytic } \\
\text { acid and titanium(IV) } \\
\text { (magGO@PEI@PA@Ti4 }{ }^{4+} \text { ) }\end{array}$ & $\begin{array}{l}\text { Nucleobases, } \\
\text { nucleosides, and } \\
\text { nucleotides }\end{array}$ & $\begin{array}{l}\text { Medicinal mushroom } \\
\text { C. Sinensis, and } \\
\text { natural foods }\end{array}$ & HPLC-DAD & $1.8-2.8 \mathrm{ng} \mathrm{mL}^{-1}$ & $\begin{array}{l}\text { Zhang Q. et al., } \\
2019\end{array}$ \\
\hline MagG@SiO $2 @ Z I F-8$ composites & Phthalate Easers & Human Plasma & GC-MS & $0.003-0.01 \mathrm{ng} \mathrm{mL}^{-1}$ & Lu et al., 2019b \\
\hline $\begin{array}{l}\text { Multi-templates molecularly imprinted } \\
\text { polymer (MIP) on the surface of } \\
\text { mesoporous silica-coated magnetic } \\
\text { graphene oxide (MGO@mSiO } \mathrm{m}_{2} \text { ), }\end{array}$ & Alkylphenols & Water & HPLC-DAD & $0.010-0.013 \mu \mathrm{g} \mathrm{L}^{-1}$ & Xie et al., 2019 \\
\hline GO & Phthalate esters & $\begin{array}{l}\text { Bottled, injectable } \\
\text { and tap waters }\end{array}$ & HPLC-UV & $0.004-0.013 \mathrm{mg} \mathrm{L}^{-1}$ & $\begin{array}{l}\text { Abdelghani et al., } \\
2019\end{array}$ \\
\hline $\mathrm{Fe}_{3} \mathrm{O}_{4} / \mathrm{rGO}$ & $\begin{array}{l}\text { Non-steroidal } \\
\text { anti-inflammatory } \\
\text { drugs and } \\
\text { bisphenol-A }\end{array}$ & Tap water & HPLC-DAD & $\begin{array}{l}0.031 \mathrm{mg} \mathrm{L}^{-1} \text { and } \\
0.023 \mathrm{mg} \mathrm{L}^{-1} \\
0.1785 \mathrm{mg} \mathrm{L}^{-1}\end{array}$ & $\begin{array}{l}\text { Ungku Abdullah } \\
\text { et al., } 2019\end{array}$ \\
\hline $\mathrm{rGO} / \mathrm{ZnFe}_{2} \mathrm{O}_{4}$ nanocomposite & Estrogens & Water, soil, and fish & $\begin{array}{l}\text { UHPLC-QTOF- } \\
\text { MS }\end{array}$ & $0.01-0.02 \mathrm{ng} \mathrm{mL}^{-1}$ & Li W. et al., 2020 \\
\hline $\begin{array}{l}\text { Polydopamine functionalized magnetic } \\
\text { graphene (PDA@MG) }\end{array}$ & Triazole fungicides & Water & HPLC-UV & 4.8-8.4 ng $L^{-1}$ & Xiong et al., 2019 \\
\hline $\begin{array}{l}\text { zeolitic imidazolate } \\
\text { framework-7@graphene oxide } \\
\text { (mag-ZIF-7@GO) }\end{array}$ & Fungicides & $\begin{array}{l}\text { Water and soil } \\
\text { samples }\end{array}$ & $\begin{array}{l}\text { HPLC-Orbitrap } \\
\text { HRMS }\end{array}$ & $0.58-2.38 \mathrm{ng} \mathrm{L}^{-1}$ & $\begin{array}{l}\text { Zhang S. et al., } \\
2019\end{array}$ \\
\hline
\end{tabular}


TABLE 3 | Continued

\begin{tabular}{|c|c|c|c|c|c|}
\hline Sorbent & Analytes & Matrix & Analysis & LOD & References \\
\hline $\begin{array}{l}\text { Guanidinium ionic liquid modified } \\
\text { magnetic chitosan/graphene oxide } \\
\text { nanocomposites (GIL-MCGO) }\end{array}$ & DNA & $\begin{array}{l}\text { Human whole blood } \\
\text { and } E \text {. coli cell lysate }\end{array}$ & $\star \star *$ & $\star \star$ & Liu M. et al., 2019 \\
\hline
\end{tabular}

${ }^{\star \star}$ Not specified.

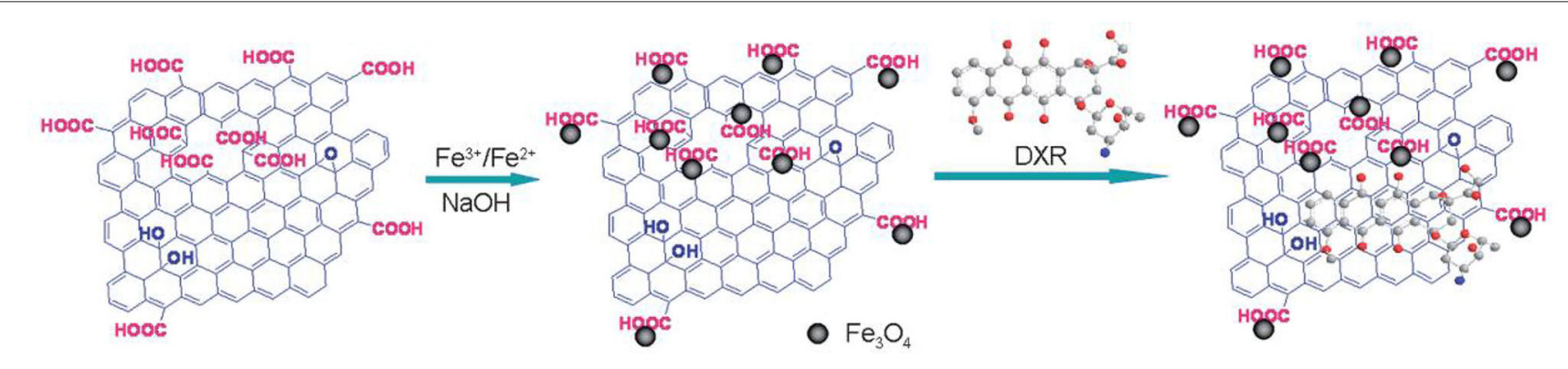

FIGURE 7 | Schematic diagram representing the synthesis of VTTS-MGO@mSiO2@MIP. Reprinted with permission from Xie et al. (2019), copyright 2019, Elsevier.

An attractive approach to obtain high performative material involves the use of the graphene-based MIP functionalized with a magnetic particle to favor the extraction and sorbent isolation. Within such a context, Ning et al. (2014) proposed a novel nanosized substrate imprinted polymer (GO-MIP- $\mathrm{Fe}_{3} \mathrm{O}_{4}$ ) on magnetic graphene oxide $\left(\mathrm{GO}-\mathrm{Fe}_{3} \mathrm{O}_{4}\right)$ surface to remove $17 \beta$ estradiol $\left(17 \beta-E_{2}\right)$ from food samples. The resulting sorbent has shown a functional extraction recovery of $84.20 \%$ at a low concentration level of $0.5 \mu \mathrm{mol} \mathrm{L} \mathrm{L}^{-1}$. Furthermore, due to the magnetic properties of the GO-MIP- $\mathrm{Fe}_{3} \mathrm{O}_{4}$, a simple, fast, and efficient separation of $17 \beta-\mathrm{E}_{2}$ were achieved, suggesting the combination between these materials as an excellent way to obtain hybrid sorbents. Following the same trend, Barati et al. (2017) synthesized a MIP based on magnetic-chitosan functionalize with GO to extract fluoxetine from environmental and biological samples. From our viewpoint, the outstanding characteristic of this work is the excellent pre-concentration factor of 500 related to such sorbent, which reinforces the combination of MIP, GBMs, and magnetic materials as an excellent way to improve sample preparation performance. Finally, another study based on a similar approach was presented by Fan et al., who prepared, through a chemical co-precipitation method, a novel hybrid sorbent based on MIP, GO, and superparamagnetic $\mathrm{Fe}_{3} \mathrm{O}_{4}$ particles (GO-MIP- $\mathrm{Fe}_{3} \mathrm{O}_{4}$ ). In this case, the author worked with natural samples, specifically alkaloids (evodiamine and rutaecarpine) extract from Evodiae Fructus, suggesting a great versatility of such magnetic GO-MIP sorbent. Also, its analytes' recovery achieves values over $82 \%$ considering as good values from our viewpoint.

Moreover, Table 4 presents other published studies to complement the discussion regarding hybrid sorbents combining MIP with GBMs.

\section{Ionic Liquids}

In 1914, a work with ionic liquids (ILs) was reported for the first time, although at that time, the author had no idea of the importance that these would take in the scientific area almost a century later (Walden, 2003). From the 1980's to the present, the interest in studying ionic liquids grew exponentially (Evans et al., 1981; Shi et al., 2015; Welton, 2018). Although they have been applied in several scientific areas, in the analytical chemistry the studies have focused mainly on the use of them for extraction, and separation purposes (Rodríguez-Sánchez et al., 2014; Tang et al., 2014; García-Alvarez-Coque et al., 2015; Marcinkowski et al., 2015; Hu et al., 2016; Yu et al., 2016; Nawała et al., 2018; Rykowska et al., 2018).

The ILs are compounds with a dual nature acting as nonpolar for nonpolar analytes and, inversely, for those with a strong proton donor group, depending on the separation mechanism that it presents (Berthod et al., 2018). Therefore, their excellent properties (high thermal stability, good solubility, and easily functionalization) have been modified in several different ways. One approach consists of replacing the anionic or cationic part with another material, of automatically regulating the IL property or nature (hydrophobicity, hydrophilicity, viscosity, and among others) (Ho et al., 2014; An et al., 2017). In this way, improvements in their sensitivity and selectivity to the extraction of the different analytes can be achieved. One of these desired enhancements is obtained by combining the ILs with GBMs, owing to their different types of chemical interactions with the analytes (e.g., $n-\pi, \pi-\pi$, hydrogen bonding, dipolar, ionic charge/charge) (Chen Y. et al., 2016; Feng et al., 2020). For these reasons, IL-GBMs present excellent extraction efficiency for a wide variety of analytes in several complex matrices (e.g., environmental, food, drinks, biological, 
TABLE 4 | Applications of MIPs-GO composite in sample pretreatment.

\begin{tabular}{|c|c|c|c|c|c|c|}
\hline Sorbent & Analytes & Matrix & $\begin{array}{l}\text { Sample } \\
\text { preparation }\end{array}$ & Analysis & LOD & References \\
\hline GO-APBA/MIP & Ovalbumin & Egg white & SDS & Gel-Electrophoresis & ** & Luo et al., 2017 \\
\hline MIPs-GO-Fe $\mathrm{O}_{4}$ & $17 \beta$-estradiol & Milk powder & External magnet & $\star \star$ & $\begin{array}{l}0.035 \text { and } 0.10 \\
\mu \mathrm{mol} \mathrm{L}^{-1}\end{array}$ & Ning et al., 2014 \\
\hline MGR@MIPs & 4-nitrophenol & Lake water & MIP & HPLC-UV & $\star \star$ & Luo et al., 2016 \\
\hline MIP-GO/Chm & Fluoxetine & $\begin{array}{l}\text { Tap, well and spring } \\
\text { water, and urine }\end{array}$ & MSPE & $\begin{array}{l}\text { UV-Vis } \\
\text { spectrophotometry }\end{array}$ & $0.03 \mu \mathrm{g} \mathrm{L}^{-1}$ & Barati et al., 2017 \\
\hline 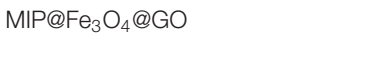 & $\begin{array}{l}\text { Evodiamine and } \\
\text { rutaecarpine }\end{array}$ & Evodiae fructus & External magnet & HPLC-UV & ** & Fan et al., 2017 \\
\hline
\end{tabular}

${ }^{\star \star}$ Not specified.

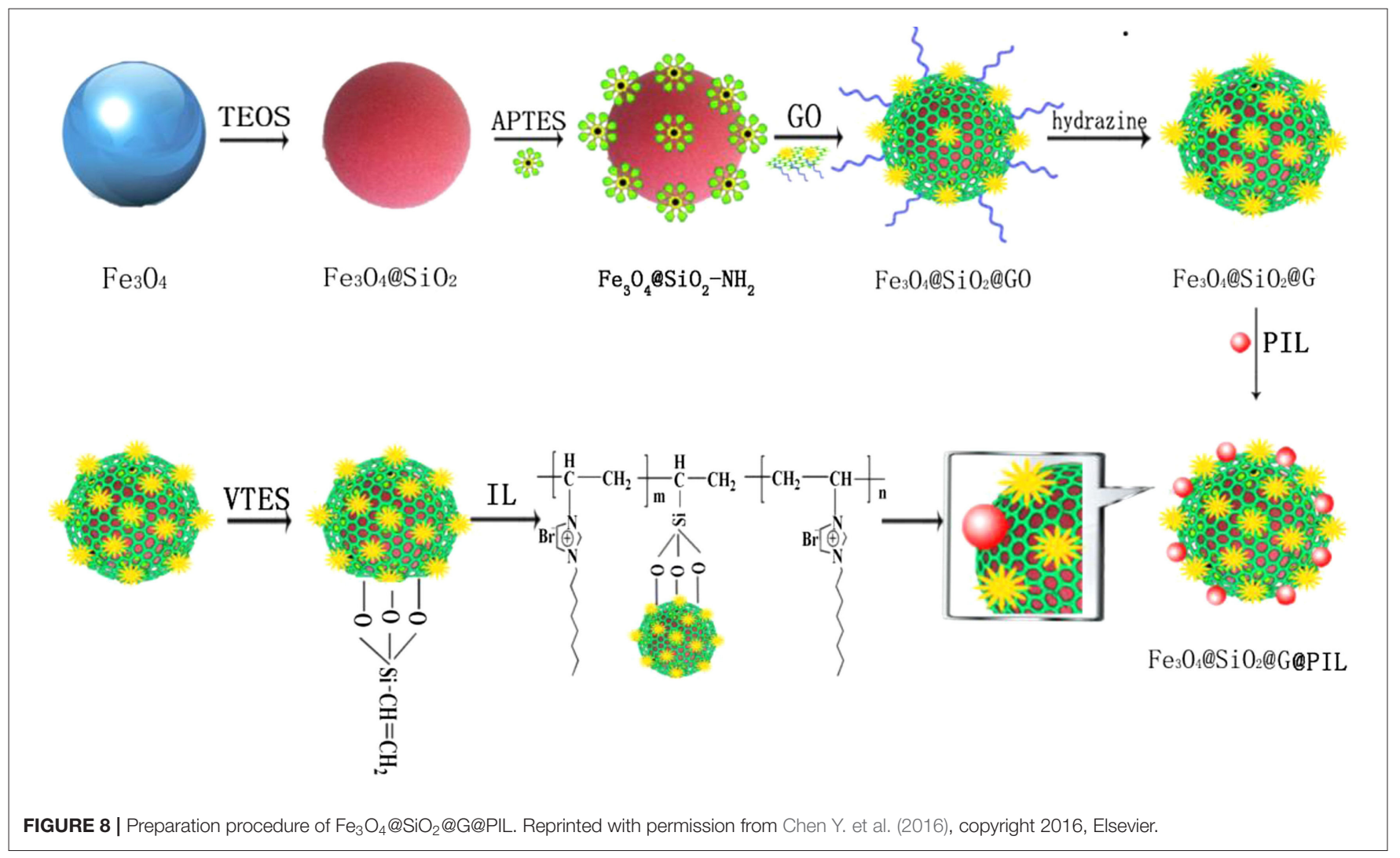

and among others), as presented. Additionally, Figure 8 illustrates a typical synthesis process performed to achieve such hybrid sorbents.

The employment of ILs combined with GMBs includes the work reported by Liu X. et al. (2019) to determine the environmentally-dangerous monocyclic heptapeptides (microcystins, MC) in natural water samples. They synthesized the IL-G by the co-precipitation route. For the analytes' extraction, the MSPE technique was used while for its separation, determination, and quantification, the authors employed UHPLC-MS/MS. For the optimization of the experimental parameters, univariate analysis, and orthogonal screening were used. The analysis time was $18 \mathrm{~min}$, with excellent linearity. The LODs were 0.414 and $0.216 \mathrm{ng} \mathrm{L}^{-1}$ for MC-LR and MC-RR, respectively, reporting traces of these two compounds in natural water samples, and it can be concluded that the method used is promising for the study of other types of microcystins in water samples. 
Other interesting applications based on IL-GBMs include work published by Chen Y. et al. (2016). They synthesized magnetite nanoparticles $\left(\mathrm{Fe}_{3} \mathrm{O}_{4}\right)$ of controlled size by a co-precipitation method to obtain the $\mathrm{Fe}_{3} \mathrm{O}_{4}-\mathrm{SiO}_{2}-\mathrm{G}-\mathrm{PIL}$ hybrid sorbent; the obtained material was used to determine preservatives in vegetables by QuEChERS following GC-MS analysis. In this study, it was possible to take advantage of the functional properties related to magnetic nanoparticles and also by its coupling to the GO with the polymeric ILs (e.g., high surface area, and solvent effects). Moreover, the method's detection limits varied between 0.82 and $6.64 \mu \mathrm{g} \mathrm{kg}^{-1}$ for the 20 preservatives studied. Similarly, Tashakkori et al. (2019) synthesized a series of ionic liquids grafted onto stainless steel wires, which were previously coated with GO, using a solgel technique. The authors used this hybrid material as a sorbent in an on-line DI-SPME-GC-MS approach to determine phthalate esters (PAE) in several samples such as tap water and seawater and coffee. They reported low detection limits (5-30 ng $\mathrm{L}^{-1}$ ) and the lab-made SPME fibers being used more than 120 times, which is a useful feature when compared with the commercially available ones such as PA and CAR/PDMS. These results reinforce the great interest in developing hybrid GBMs combined with ILS.

Additionally, biological samples were analyzed by Ding et al. (2015). They functionalized magnetic chitosan with a series of ionic liquids of guanidinium and graphene oxide, aiming to extract trypsin, lysozyme, ovalbumin, and albumins from bovine serum. In this case, the analytical results obtained by this hybrid guanidinium-IL functionalized with MCGO were compared with those achieved by employing just GO, magnetic chitosan, or MCGO. In this case, the hybrid guanidinium-IL-MCGO exhibits higher extraction performance compared to the other sorbents, which suggests the combination of GBMs and ILs as a suitable strategy to achieve more performative extractive phases. Also, Hou et al. (2016) proposed a poly(1-vinyl-3-hexylimidazolium bromide)-GO-grafted silica [poly( $\left.\mathrm{VHIm}^{+} \mathrm{Br}^{-}\right)-\mathrm{GO}-\mathrm{Sil}$ ] as a hybrid IL sorbent to extract flavonoids in urine samples. They synthesized the material by an interesting process consisting of an in situ radical chain-transfer polymerization and then in situ anion exchange. In this case, the procedure started with the silica coating by GO, using a manufacturing layer by layer fabrication method. Then, the poly $\left(\mathrm{VHIm}^{+} \mathrm{Br}^{-}\right)-\mathrm{GO}-\mathrm{Sil}$ anion was transformed into hexafluorophosphate $\left(\mathrm{PF}^{6-}\right)$ by in situ anion exchange. The method based on SPE-HPLC-UV showed acceptable extraction recoveries for four flavonoids, with limits of detection in the range of $0.1-0.5 \mu \mathrm{g} \mathrm{L}^{-1}$. The proposed material showed ecological and cost-effective advantages. It can be applied successfully to the extraction and enrichment of flavonoids in human samples, even allowing the study of metabolic kinetics.

Finally, considering other types of samples, an interesting study published by Zhou et al. (2016) was carried out to analyze phthalates (PAE) in eraser samples. The Office of Quality and Technology Supervision of the province of Jiangsu in China required PAE analyses in several samples to maintain concentrations inside the accepted limits registered by law. For this reason, it is necessary to monitor residues of this compound not only in food but also in everyday objects used by people
(Zhou et al., 2016). Within such a context, a new graphene oxide compound modified with ionic liquids (GO-[AEMIM][Br]) was synthesized through an amidation reaction between the amino groups of the ILs and the carboxyl groups of GO. The high extraction capacity reported by this hybrid sorbent suggests the combination of the properties of ILs and GBMs (tunability and high surface area) as a positive relationship that assisted the PAE extraction in such a non-common sample.

Apart from the interesting application herein discussed, other relevant studies based on hybrid sorbents combining IL and GBMs are shown in Table 5.

\section{Miscellaneous}

This section aims to present some alternative graphene-based materials that could be an alternative for the sample preparation in the future. For this reason, there are not many publications apart from the materials already discussed in the previous sections. An original example recently published by Tahmasebi (2018) consisted of intercalating aluminum polyoxocations $\left(\mathrm{Al}_{30}\right)$ between the graphene oxide $(\mathrm{GO})$ nanosheets and further support this onto polycaprolactone nanofibers, aiming to enhance temperature, and $\mathrm{pH}$ resistance to the sorbent phase. This novel material was applied in SPE extraction of four statin drugs showing acceptable analytical performance. The author emphasized the excellent ability of this sorbent to interact with acidic polar species, possibly due to the resistance to $\mathrm{pH}$ variations. Another interesting application was performed by Li et al. (2014) whose synthesized a magnetic ionic liquid/chitosan/GO (MCGO-IL) as a biodegradable/biosorbent for the mitigation of $\mathrm{Cr}$ (IV) in the treatment of residual in environmental water samples. A solid-liquid separation was performed in the presence of an external magnetic field, involving a pseudo-second-order kinetic sorption step. The maximum adsorption capacity was $145.35 \mathrm{mg} \mathrm{g}^{-1}$, obtained thanks to the intermolecular hydrogen bond between MCGO-IL and $\mathrm{Cr}(\mathrm{IV})$, due to the hydroxy and amine groups to which the ions bind metallic. This result demonstrates the potential of this hybrid sorbent material in the cleaning processes of contaminating metal ions in complex matrices such as water. Additionally, the authors emphasize its low producing cost as a useful characteristic since commercially available sorbents often are expensive and non-reusable.

Additionally, the more significant interlayer distance between $\mathrm{GO}$ sheets, due to $\mathrm{Al}_{30}$ insertions, can enhance the interaction with the $\pi$-electron system onto the GO surface, resulting in enhanced extraction performance. Similarly, Amiri et al. (2019) synthesized another hybrid sorbent but this time supporting GO nanosheets with polyoxotungstate (POT), instead of $\mathrm{Al}$, to enhance chemical stability and $\mathrm{pH}$ resistance once POT act as charge-compensating and space-filling compound. This strategy is proposed to enhance the POT water dispersibility and surface area of the sorbent, possibly favoring the extraction performance while ensuring its high thermal and $\mathrm{pH}$ stability. Another strategy, underscored by Farajvand et al. (2018), was to covalently-bond an electrically conducting polymers onto the GO surface to diminish its self-aggregation in aqueous as well as enhance adsorption capacity. In this case, polyaniline was used 
TABLE 5 | Applications of Ils-GO composite in sample pretreatment.

\begin{tabular}{|c|c|c|c|c|c|c|}
\hline Sorbent & Analyte & Matrix & $\begin{array}{l}\text { Sample } \\
\text { preparation }\end{array}$ & Analysis & LOD & References \\
\hline IL-GO@Silica & Chlorophenols & Water & SPE & HPLC-UV & $* *$ & Wang et al., 2017a \\
\hline$\left[\mathrm{C}_{4} \mathrm{C}_{12} \mathrm{im}\right] @ \mathrm{GO}$ & $\mathrm{Hg}$ & Water & SPE & AAS & $14 \mathrm{ng} \mathrm{L}^{-1}$ & $\begin{array}{l}\text { Sotolongo et al., } \\
2018\end{array}$ \\
\hline MGONPs- ${ }_{16} \mathrm{mimBr}$ & Chlorophenols & Water & MSPE & HPLC-UV & $\begin{array}{l}0.10-0.13 \mu \mathrm{g} \\
\mathrm{L}^{-1}\end{array}$ & Liu W. et al., 2017 \\
\hline PGO-MILN & Chlorophenols & Water & MSPE & LC-MS/MS & $0.2-2.6 \mathrm{ng} \mathrm{L}^{-1}$ & Cai et al., 2016 \\
\hline $\begin{array}{l}\text { GO-1-butyl-3-aminopropyl imidazolium } \\
\text { chloride. }\end{array}$ & $\begin{array}{l}\text { Anabolic } \\
\text { steroids } \\
\beta \text {-blockers }\end{array}$ & Water & SPE & HPLC-DAD & $7-23 \mathrm{ng} \mathrm{L}^{-1}$ & $\begin{array}{l}\text { Serrano et al., } \\
2016\end{array}$ \\
\hline rGO/ILN-ETD & Estrogens & Milk & ETD & HPLC-DAD & $\begin{array}{l}0.09-0.30 \mu \mathrm{g} \\
\mathrm{L}^{-1}\end{array}$ & Chu et al., 2019 \\
\hline $\begin{array}{l}\text { 1-(3-aminopropyl)-3-vinyl imidazolium } \\
\text { bromide/tetrafluoroborate) grafted }\end{array}$ & Phthalate Esters & $\begin{array}{l}\text { Coffee } \\
\text { Tap Water } \\
\text { Seawater }\end{array}$ & SPME & GC-MS & $5-30 \mathrm{ng} \mathrm{L}^{-1}$ & $\begin{array}{l}\text { Tashakkori et al., } \\
2019\end{array}$ \\
\hline PANI-MWCNTS-rGO-IL & Alcohols & Tea & SPME & GC-FID & 2.2-28.3 ng L $\mathrm{L}^{-1}$ & Li et al., 2016 \\
\hline IL-TGO & Auxins & Soybean sprouts & PT-SPE & HPLC-DAD & $\begin{array}{l}0.004-0.026 \mu \mathrm{g} \\
g^{-1}\end{array}$ & $\begin{array}{l}\text { Zhang H. et al., } \\
2018\end{array}$ \\
\hline MGO-C ${ }_{16}$ MIM-DMG & Trace nickel & $\begin{array}{l}\text { Spinach } \\
\text { Cacao powder } \\
\text { Tea } \\
\text { Cigarette }\end{array}$ & MSPE & FAAS & $0.16 \mu \mathrm{g} \mathrm{L}^{-1}$ & Aliyari et al., 2016 \\
\hline Magnetic GO/PPy & Methotrexate & Urine & d-SPE & HPLC-UV & $7 \mathrm{ng} \mathrm{mL}^{-1}$ & Hamidi et al., 2019 \\
\hline $3 \mathrm{D}-\mathrm{IL}-\mathrm{Fe}_{3} \mathrm{O}_{4}-\mathrm{GO}$ & PAHs & Human blood & PT-SPE & GC-MS & $\begin{array}{l}0.002-0.004 \mu \mathrm{g} \\
\mathrm{L}^{-1}\end{array}$ & $\begin{array}{l}\text { Zhang Y. et al., } \\
2018\end{array}$ \\
\hline $\mathrm{PIL}(\mathrm{Br})-\mathrm{G} / \mathrm{SiO}_{2}$ & $\begin{array}{l}\text { Human serum } \\
\text { albumin }\end{array}$ & $\begin{array}{l}\text { Human whole } \\
\text { blood }\end{array}$ & SPE & HPLC-UV & ** & Liu et al., 2018 \\
\hline $\mathrm{Fe}_{3} \mathrm{O}_{4} / \mathrm{GO}$ NPs & Cephalosporins & Urine & MSPE & HPLC-UV & $\begin{array}{l}0.6 \text { and } 1.9 \mathrm{ng} \\
\mathrm{mL}^{-1}\end{array}$ & Wu et al., 2016 \\
\hline GO-[AEMIM][Br] & Phthalates & Eraser & SPE & HPLC-UV & $\begin{array}{l}0.02-0.88 \mathrm{ng} \\
\mathrm{mL}^{-1}\end{array}$ & Zhou et al., 2016 \\
\hline
\end{tabular}

${ }^{\star *}$ Not specified.

considering its various oxidation states possessing distinct charge carriers which allow chemical interactions with several heavy metals. In this case, this sorbent was tested for $\mathrm{Cd}$ isolation from environmental water samples by SPE and subsequent dispersive liquid-liquid extraction.

In general, all these modifications performed in the $G$ or GO chemical structures aim to improve its performance. However, a work published by Ashori et al. seems to follow the reverse trend focusing on using the graphene oxide as a reinforcement for glass fiber and epoxy composites. For this reason, the primary goals were to improve chemical reactivity, toughness, and adhesion to polymeric matrices, including the GO's widely-known properties. Although this material had not been applied for sample preparation yet, its high mechanical strength might be a promising tool particularly for miniaturized sample preparation techniques once they often demand highpressure procedures causing clogging problems when GO or G are applied as sorbents. Recently, another interesting compound, 
namely graphene-aerogel, has gained attention mainly due to its superior and tunable volume as well as surface area as compared to graphene. The aerogel only itself exhibits poor extraction performance for water-soluble analytes, thus demanding some modification on it, as the functionalization of graphenebased compounds. In this way, graphene-based aerogels are suitable for sample preparation since they can relate the great qualities of graphene with the impressive compressibility of aerogels. Therefore, high-performance sorbents packed into sample preparation hardware can be reusable many times, considering the compressibility factor, which can help unpack and recover these extractive phases. As examples, Maggira et al. (2019) and Tang S. et al. (2019) reported two selfrecoverable graphene-aerogels which were successfully applied to the analysis of sulfonamides and phenolic compounds in complex matrices, respectively.

Considering the impressive arising of graphene-based sorbents throughout the last years, herein, we aimed to pinpoint some of the unusual approached to perform such modifications and production of extractive phase. However, novel sorbent phases can be expected to be developed daily, considering the great qualities of nanomaterials for analytical chemistry purposes, highlighting the graphene.

\section{CONCLUDING REMARKS}

Bearing in mind the great importance of sample preparation to clean-up samples, extract, and pre-concentrate target analytes become easier to understand the increasing interest of the analytical chemistry in developing modern strategies to optimize such a critical stage. In this context, one of the most relevant and promising fields is the development of more performative and environmentally-friend sorption-based techniques and, by consequence, the sorbents commonly used on them. As it is known, a good sorbent material must have some essential characteristics, including (i) selectivity for specific analytes and thus present chemical inertia for matrix interferents; (ii) good recovery and enrichment factors; and (iii) simple and non-expensive production. Once fulfilling these requirements, graphene-based materials have increasingly seemed to be the right candidate since their first application in sample preparation around 2011. Its large surface area, together with the $\pi-\pi$ delocalized electron system, aid in improving so much the extraction performance of target compounds possessing aromatic rings as several chemical classes (e.g., pesticides, pharmaceuticals, and others) as herein discussed on section Graphene and Graphene Oxide.

Although the successful application in its "bare" form (G and GO), sometimes the functionalization of them seems to enhance even more the performance of such sorbents. For this reason, in this work, we have shown several different applications based on the use of hybrid materials consisting of GBMs anchored to other extractive sorbents such as alkyl and aryl groups, cyclodextrins, magnetic particles, molecularly imprinted polymers, ionic liquids, and among others. The functionalization is often achieved by forming covalent or hydrogen bondings, using sol-gel or polymerization router, or even electrochemical deposition. This interesting approach is encouraged by the possibility to ally the advantages of each class in only one. Apart from this goal, the clogging and backpressure problems often related to $\mathrm{G}$ and $\mathrm{GO}$ when packed in sorbent-based sample preparation techniques are overcome by the addition of other compounds. For example, several works underscored in sections Alkyl and Aril Groups, Cyclodextrins, and Magnetic Materials based on magnetic particles, or anchoring in silica reported this result.

Similarly, increasing on extraction selectivity and by consequence, performance is observed when GBMs were functionalized with both MIPS or the tunable-ILs, as can be seen in sections Molecularly-Imprinted Polymers and Ionic Liquids. This background explains the significant tendency to work with hybrid graphene-based materials instead of its bare form. GBMs are an excellent sorbent, often surpassing the commercially available phases such as $\mathrm{C} 8$ and C18.

After all, by assessing the recent literature and considering the vast number of applications involving graphene in the sample preparation arena, as herein discussed, an increasing tendency to expand the footprint of GBMs functionalized with several classes must continue in the years to come. This conclusion is mainly supported by the unique favorable GBMs physical-chemical properties, which-together with the advancements on the materials synthesis routes, extraction techniques, and related subjects-evidenced this field as one of the most critical developments in the sample preparation area nowadays. Also, an increasing number of papers reporting the employment of hybrid GBMs and miniaturized sample preparation techniques must be expected. This trend can be projected considering the high potential obtained by combining the well-established benefits of automation/miniaturization with the use of more selective and performative materials, possibly leading to greener sample preparation techniques by following the Green Chemistry concept.

\section{AUTHOR CONTRIBUTIONS}

EM wrote sections Introduction, Miscellaneous, and Concluding Remarks, as well as edited the whole manuscript. KM-C wrote sections Graphene and Graphene Oxide and Alkyl and Aril Groups, built Table 1, and revised the whole manuscript. MJ-S wrote sections Molecularly-Imprinted polymers and Ionic Liquids, as well as built Tables 4, 5. LS wrote section Cyclodextrins and built Table 2. DV wrote section Magnetic Materials and built Table 3. FL conceptualized, supervised, and edited all versions of the manuscript, as well as provide all required facilities. All authors contributed to the article and approved the submitted version.

\section{FUNDING}

The authors are grateful to FAPESP (Grants 2017/02147-0, 2015/15462-5, and 2014/07347-9) and CNPq (307293/2014-9) for the financial support provided. This research project was financed in part by the Coordenação de Aperfeiçoamento de Pessoal de Nível Superior-Brasil (CAPES)_Finance Code 001. 


\section{REFERENCES}

Abdelghani, J. I., Freihat, R. S., and El-sheikh, A. H. (2019). Magnetic solid phase extraction of phthalate products from bottled, injectable and tap waters using graphene oxide : effect of oxidation method of graphene. J. Environ. Chem. Eng. 8:103527. doi: 10.1016/j.jece.2019.103527

Abdolmohammad-zadeh, H., Zamani, A., and Shamsi, Z. (2019). Preconcentration of morphine and codeine using a magnetite/reduced graphene oxide/silver nano-composite and their determination by high-performance liquid chromatography. J. Chromatogr. A 1590, 2-9. doi: $10.1016 /$ j.chroma.2018.12.064

Abdolmohammad-zadeh, H. (2020). A simple magnetic solid-phase extraction method based on magnetite/graphene oxide nanocomposite for preconcentration and determination of melamine by high-performance liquid chromatography. Environ. Sci. Pollut. Res. 27, 9826-9834. doi: $10.1007 / \mathrm{s} 11356-020-07681-\mathrm{z}$

Alasl, M. R. K., Sohrabi, M. R., and Davallo, M. (2019). Determination of trace amounts of aromatic amines after magnetic solid-phase extraction using silver-modified Fe3O4/graphene nanocomposite. J. Sep. Sci. 42, 1777-1785. doi: 10.1002/jssc.201800896

Aliyari, E., Alvand, M., and Shemirani, F. (2016). Modified surface-active ionic liquid-coated magnetic graphene oxide as a new magnetic solid phase extraction sorbent for preconcentration of trace nickel. RSC Adv. 6, 64193-64202. doi: 10.1039/C6RA04163A

Allen, M. J., Tung, V. C., and Kaner, R. B. (2010). Honeycomb carbon: a review of graphene. Chem. Rev. 110, 132-145. doi: 10.1021/cr900070d

Amiri, A., Mirzaei, M., and Derakhshanrad, S. (2019). A nanohybrid composed of polyoxotungstate and graphene oxide for dispersive micro solid-phase extraction of non-steroidal anti-inflammatory drugs prior to their quantitation by HPLC. Microchim. Acta 18:6534. doi: 10.1007/s00604-019-3694-0

An, J., Rahn, K. L., and Anderson, J. L. (2017). Headspace single drop microextraction versus dispersive liquid-liquid microextraction using magnetic ionic liquid extraction solvents. Talanta 167, 268-278. doi: 10.1016/j.talanta.2017.01.079

Asadi, M., Sereshti, H., and Rashidi Nodeh, H. (2020). Development of magnetic dispersive microsolid-phase extraction using lanthanum phosphate nanoparticles doped on magnetic graphene oxide as a highly selective adsorbent for pesticide residues analysis in water and fruit samples. Res. Chem. Intermed. 46, 2789-2803. doi: 10.1007/s11164-020-04121-y

Barati, A., Kazemi, E., Dadfarnia, S., and Haji Shabani, A. M. (2017). Synthesis/characterization of molecular imprinted polymer based on magnetic chitosan/graphene oxide for selective separation/preconcentration of fluoxetine from environmental and biological samples. J. Ind. Eng. Chem. 46, 212-221. doi: 10.1016/j.jiec.2016.10.033

Berthod, A., Ruiz-Ángel, M. J., and Carda-Broch, S. (2018). Recent advances on ionic liquid uses in separation techniques. J. Chromatogr. A 1559, 2-16. doi: 10.1016/j.chroma.2017.09.044

Bottari, G., Ángeles Herranz, M., Wibmer, L., Volland, M., RodríguezPérez, L., Guldi, D. M., et al. (2017). Chemical functionalization and characterization of graphene-based materials. Chem. Soc. Rev. 46, 4464-4500. doi: 10.1039/C7CS00229G

Cai, M. Q., Su, J., Hu, J. Q., Wang, Q., Dong, C. Y., Pan, S. D., et al. (2016). Planar graphene oxide-based magnetic ionic liquid nanomaterial for extraction of chlorophenols from environmental water samples coupled with liquid chromatography-tandem mass spectrometry. J. Chromatogr. A 1459, 38-46. doi: 10.1016/j.chroma.2016.06.086

Cao, S., Chen, J., Lai, G., Xi, C., Li, X., Zhang, L., et al. (2019). A high efficient adsorbent for plant growth regulators based on ionic liquid and $\beta$-cyclodextrin functionalized magnetic graphene oxide. Talanta 194, 14-25. doi: 10.1016/j.talanta.2018. 10.013

Chandra, V., Park, J., Chun, Y., Lee, J. W., Hwang, I., and Kim, K. S. (2010). Waterdispersible magnetite-reduced graphene oxide composites for arsenic removal. ACS Nano 4, 3979-3986. doi: 10.1021/nn1008897

Chatzimitakos, T. G., Karali, K. K., and Stalikas, C. D. (2019). Magnetic graphene oxide as a convenient nanosorbent to streamline matrix solid-phase dispersion towards the extraction of pesticides from vegetables and their determination by GC-MS. Microchem. J. 151:104247. doi: 10.1016/j.microc.2019.104247
Chen, X., Hai, X., and Wang, J. (2016). Graphene/graphene oxide and their derivatives in the separation/isolation and preconcentration of protein species: a review. Anal. Chim. Acta 922, 1-10. doi: 10.1016/j.aca.2016.03.050

Chen, X., and Ye, N. (2017). A graphene oxide surface-molecularly imprinted polymer as a dispersive solid-phase extraction adsorbent for the determination of cefadroxil in water samples. RSC Adv. 7, 34077-34085. doi: 10.1039/C7RA02985C

Chen, Y., Cao, S., Zhang, L., Xi, C., Li, X., Chen, Z., et al. (2016). Preparation of size-controlled magnetite nanoparticles with a graphene and polymeric ionic liquid coating for the quick, easy, cheap, effective, rugged and safe extraction of preservatives from vegetables. J. Chromatogr. A 1448, 9-19. doi: 10.1016/j.chroma.2016.04.045

Cheng, L., Pan, S., Ding, C., He, J., and Wang, C. (2017). Dispersive solidphase microextraction with graphene oxide based molecularly imprinted polymers for determining bis(2-ethylhexyl) phthalate in environmental water. J. Chromatogr. A 1511, 85-91. doi: 10.1016/j.chroma.2017.07.012

Chu, F., Gao, M., Wang, H., Li, J., Zheng, Z., Wang, X., et al. (2019). Development of an effervescent reaction-enhanced microextraction method for preconcentration/extraction of trace estrogens in milk using a reduced graphene oxide-assisted ionic liquid-based nanofluid. Anal. Methods 11, 3608-3618. doi: 10.1039/C9AY00803A

De Marchi, L., Pretti, C., Gabriel, B., Marques, P. A. A. P., Freitas, R., and Neto, V. (2018). An overview of graphene materials: properties, applications and toxicity on aquatic environments. Sci. Total Environ. 631-632, 1440-1456. doi: 10.1016/j.scitotenv.2018.03.132

De Silva, K. K. H., Huang, H. H., Joshi, R. K., and Yoshimura, M. (2017). Chemical reduction of graphene oxide using green reductants. Carbon N. Y. 119, 190-199. doi: 10.1016/j.carbon.2017.04.025

De Toffoli, A. L., Fumes, B. H., and Lanças, F. M. (2018). Packed in-tube solid phase microextraction with graphene oxide supported on aminopropyl silica: determination of target triazines in water samples. J. Environ. Sci. Heal. B 53, 434-440. doi: 10.1080/03601234.2018.1438831

Deng, J., Zhang, P., Jin, T., Zhou, H., and Cheng, J. (2017). Graphene oxide/ $\beta$-cyclodextrin composite as fiber coating for high efficiency headspace solid phase microextraction of organophosphate ester flame retardants in environmental water. RSC Adv. 7, 54475-54484. doi: 10.1039/C7RA07903F

Ding, X., Wang, Y., Wang, Y., Pan, Q., Chen, J., Huang, Y., et al. (2015). Preparation of magnetic chitosan and graphene oxide-functional guanidinium ionic liquid composite for the solid-phase extraction of protein. Anal. Chim. Acta 861, 36-46. doi: 10.1016/j.aca.2015.01.004

Dramou, P., Itatahine, A., Fizir, M., and Ait, Y. (2019). Preparation of novel molecularly imprinted magnetic graphene oxide and their application for quercetin determination. J. Chromatogr. B 1124, 273-283. doi: 10.1016/j.jchromb.2019.06.007

Dreyer, D. R., Park, S., Bielawski, C. W., and Ruoff, R. S. (2010). The chemistry of graphene oxide. Chem. Soc. Rev. 39, 228-240. doi: 10.1039/B917103G

Esfandiarnejad, R., and Sereshti, H. (2019). Designing an absolutely solventfree binary extraction system as a green strategy for ultra-trace analysis of chlorophenols. Microchem. J. 146, 701-707. doi: 10.1016/j.microc.2019.01.072

Evans, D. F., Chen, S.-H., Schriver, G. W., and Arnett, E. M. (1981). Thermodynamics of solution of nonpolar gases in a fused salt. Hydrophobic bonding behavior in a nonaqueous system. J. Am. Chem. Soc. 103, 481-482. doi: 10.1021/ja00392a049

Evrim, S., Tekkeli, K., and Durmus, Z. (2019). Magnetic solid phase extraction applications combined with analytical methods for determination of drugs in different matrices review. J. Chil. Chem. Soc. 2, 4448-4458. doi: 10.4067/S0717-97072019000204448

Fan, J.-P., Liao, D.-D., Xie, Y.-L., Zheng, B., Yu, J.-X., Cao, Y.-H., et al. (2017). A molecular imprinted polymer on the surface of superparamagnetic Fe $3 \mathrm{O}$ 4 -graphene oxide (MIP@Fe 3 O $4 @$ GO) for simultaneous recognition and enrichment of evodiamine and rutaecarpine in Evodiae fructus. J. Appl. Polym. Sci. 134, 1-9. doi: 10.1002/app.44465

Fang, X., Chen, G., Qiu, J., Xu, J., Wang, J., Zhu, F., et al. (2018). Determination of four salicylic acids in aloe by in vivo solid phase microextraction coupling with liquid chromatography-photodiode array detection. Talanta 184, 520-526. doi: $10.1016 /$ j.talanta.2018.03.043

Farajvand, M., Farajzadeh, K., and Faghani, G. (2018). Synthesis of graphene oxide/polyaniline nanocomposite for measuring cadmium(II) by solid phase 
extraction combined with dispersive liquid-liquid microextraction. Mater. Res. Express 5:075017. doi: 10.1088/2053-1591/aace3a

Farzin, L., Shamsipur, M., and Sheibani, S. (2016). Solid phase extraction of hemin from serum of breast cancer patients using an ionic liquid coated Fe3O4/graphene oxide nanocomposite, and its quantitation by using FAAS. Microchim. Acta 183, 2623-2631. doi: 10.1007/s00604-016-1906-4

Feng, J., Loussala, H. M., Han, S., Ji, X., Li, C., and Sun, M. (2020). Recent advances of ionic liquids in sample preparation. TrAC Trends Anal. Chem. 125:115833. doi: $10.1016 /$ j.trac.2020.115833

Feng, Y., Hu, X., Zhao, F., and Zeng, B. (2019). Fe 3 O 4 /reduced graphene oxide-carbon nanotubes composite for the magnetic solid-phase extraction and HPLC determination of sulfonamides in milk. J. Sep. Sci. 42, 1058-1066. doi: $10.1002 /$ jssc. 201801177

Feriduni, B. (2019). Magnetic graphene oxide-based solid-phase extraction combined with dispersive liquid-liquid microextraction for the simultaneous preconcentration of four typical pesticide residues in fruit juice and pulp. Food Analytical Methods 12, 2742-2752. doi: 10.1007/s12161-019-01635-Z

Ferrone, V., Todaro, S., Carlucci, M., Fontana, A., Ventrella, A., Carlucci, G., et al. (2020). Optimization by response surface methodology of a dispersive magnetic solid phase extraction exploiting magnetic graphene nanocomposite coupled with UHPLC-PDA for simultaneous determination of new oral anticoagulants (NAOs) in human plasma. J. Pharm. Biomed. Anal. 179:112992. doi: $10.1016 /$ j.jpba.2019.112992

Filik, H., and Avan, A. A. (2019). Magnetic nanostructures for preconcentration, speciation and determination of chromium ions : a review. Talanta 203, 168-177. doi: 10.1016/j.talanta.2019.05.061

Fontanals, N., Marcé, R. M., and Borrull, F. (2020). "Porous polymer sorbents," in Solid-Phase Extraction, ed C. F. Poole (Amsterdam: Elsevier), 55-82. doi: 10.1016/B978-0-12-816906-3.00003-0

Fumes, B. H., and Lanças, F. M. (2017). Use of graphene supported on aminopropyl silica for microextraction of parabens from water samples. J. Chromatogr. A 1487, 64-71. doi: 10.1016/j.chroma.2017.01.063

Fumes, B. H., Silva, M. R., Andrade, F. N., Nazario, C. E. D., and Lanças, F. M. (2015). Recent advances and future trends in new materials for sample preparation. TrAC Trends Anal. Chem. 71, 9-25. doi: 10.1016/j.trac.2015.04.011

García-Alvarez-Coque, M. C., Ruiz-Angel, M. J., Berthod, A., and Carda-Broch, S. (2015). On the use of ionic liquids as mobile phase additives in highperformance liquid chromatography. a review. Anal. Chim. Acta 883, 1-21. doi: 10.1016/j.aca.2015.03.042

Geim, A. K. (2009). Graphene: status and prospects. Science 324, 1530-1534. doi: $10.1126 /$ science. 1158877

Geim, A. K., and Novoselov, K. S. (2007). The rise of graphene. Nat. Mater. 6, 183-191. doi: 10.1038/nmat1849

Gentili, A. (2020). Cyclodextrin-based sorbents for solid phase extraction. J. Chromatogr. A 1609:460654. doi: 10.1016/j.chroma.2019.460654

González-Sálamo, J., Socas-Rodríguez, B., Hernández-Borges, J., and RodríguezDelgado, M. Á. (2016). Nanomaterials as sorbents for food sample analysis. TrAC 85, 203-220. doi: 10.1016/j.trac.2016.09.009

Grajek, H., Jonik, J., Witkiewicz, Z., Wawer, T., and Purchała, M. (2019). Applications of graphene and its derivatives in chemical analysis. Crit. Rev. Anal. Chem. 7, 1-27. doi: 10.1080/10408347.2019.1653165

Hamidi, S., Azami, A., and Mehdizadeh Aghdam, E. (2019). A novel mixed hemimicelles dispersive micro-solid phase extraction using ionic liquid functionalized magnetic graphene oxide/polypyrrole for extraction and pre-concentration of methotrexate from urine samples followed by the spectrophotometric method. Clin. Chim. Acta 488, 179-188. doi: 10.1016/j.cca.2018.11.006

Han, S., Li, X., Wang, Y., and Chen, S. (2015). Multifunctional imprinted polymers based on $\mathrm{CdTe} / \mathrm{CdS}$ and magnetic graphene oxide for selective recognition and separation of p-t-octylphenol. Chem. Eng. J. 271, 87-95. doi: 10.1016/j.cej.2015.02.080

Ho, T. D., Zhang, C., Hantao, L. W., and Anderson, J. L. (2014). Ionic liquids in analytical chemistry: fundamentals, advances, and perspectives. Anal. Chem. 86, 262-285. doi: 10.1021/ac4035554

Hou, X., Liu, S., Zhou, P., Li, J., Liu, X., Wang, L., et al. (2016). Polymeric ionic liquid modified graphene oxide-grafted silica for solidphase extraction to analyze the excretion-dynamics of flavonoids in urine by box-behnken statistical design. J. Chromatogr. A 1456, 10-18. doi: 10.1016/j.chroma.2016.05.096

Hou, X., Lu, X., Tang, S., Wang, L., and Guo, Y. (2018a). Graphene oxide reinforced ionic liquid-functionalized adsorbent for solid-phase extraction of phenolic acids. J. Chromatogr. B 1072, 123-129. doi: 10.1016/j.jchromb.2017.11.013

Hou, X., Tang, S., Guo, X., Wang, L., Liu, X., Lu, X., et al. (2018b). Preparation and application of guanidyl-functionalized graphene oxide-grafted silica for efficient extraction of acidic herbicides by Box-Behnken design. J. Chromatogr. A 1571, 65-75. doi: 10.1016/j.chroma.2018.08.030

Hou, X., Tang, S., and Wang, J. (2019). Recent advances and applications of graphene-based extraction materials in food safety. $\operatorname{Tr} A C$ 119:115603. doi: 10.1016/j.trac.2019.07.014

Hu, H., Liu, B., Yang, J., Lin, Z., and Gan, W. (2016). Sensitive determination of trace urinary 3-hydroxybenzo[a]pyrene using ionic liquids-based dispersive liquid-liquid microextraction followed by chemical derivatization and high performance liquid chromatography-high resolution tandem mass spectrometry. J. Chromatogr. B Anal. Technol. Biomed. Life Sci. 1027, 200-206. doi: 10.1016/j.jchromb.2016.05.041

Hummers, W. S., and Offeman, R. E. (1958). Preparation of graphitic oxide. J. Am. Chem. Soc. 80, 1339-1339. doi: 10.1021/ja01539a017

Iakunkov, A., Sun, J., Rebrikova, A., Korobov, M., Klechikov, A., Vorobiev, A., et al. (2019). Swelling of graphene oxide membranes in alcohols: effects of molecule size and air ageing. J. Mater. Chem. A 7, 11331-11337. doi: 10.1039/C9TA01902B

Ibarra, I. S., Rodriguez, J. A., Galán-vidal, C. A., Cepeda, A., and Miranda, J. M. (2015). Magnetic solid phase extraction applied to food analysis. J. Chem. 2015, 1-13. doi: 10.1155/2015/919414

Ibrahim, H., Yilmaz, E., and Soylak, M. (2019). Magnetic solid phase extraction of trace paracetamol and caffeine in synthetic urine and wastewater samples by a using core shell hybrid material consisting of graphene oxide/multiwalled carbon nanotube/Fe3O4/SiO2. Microchem. J. 145, 843-851. doi: 10.1016/j.microc.2018.11.056

Jing, W., Zhou, Y., Wang, J., Ni, M., Bi, W., Da, D., et al. (2019). Dispersive magnetic solid-phase extraction coupled to direct analysis in real time mass spectrometry for high-throughput analysis of trace environmental contaminants. Anal. Chem. 91, 11240-11246. doi: 10.1021/acs.analchem.9b02197

Klongklaew, P., Naksena, T., Kanatharana, P., and Bunkoed, O. (2018). A hierarchically porous composite monolith polypyrrole/octadecyl silica/graphene oxide/chitosan cryogel sorbent for the extraction and pre-concentration of carbamate pesticides in fruit juices. Anal. Bioanal. Chem. 410, 7185-7193. doi: 10.1007/s00216-018-1323-0

Landau, L. (1937). Zur theorie der phasenumwandlungen II. Phys. Zeitschrift der Sowjetunion 11, 26-35.

Lang, H., Yang, R., Dou, X., Wang, D., Zhang, L., and Li, J. (2019). Simultaneous determination of 19 phenolic compounds in oilseeds using magnetic solid phase extraction and LC-MS/MS. LWT Food Sci. Technol. 107, 221-227. doi: 10.1016/j.lwt.2019.03.018

Laura, A., Chiara, C., Giorgia, C., Barbera, L., Maria, C., Susy, M., et al. (2019). Recent applications of magnetic solid-phase extraction for sample preparation. Chromatographia 82, 1251-1274. doi: 10.1007/s10337-019-03721-0

Li, F., Huang, Y., Huang, K., Lin, J., and Huang, P. (2020). Functional magnetic graphene composites for biosensing. Int. J. Mol. Sci. 21:390. doi: 10.3390/ijms21020390

Li, L., Luo, C., Li, X., Duan, H., and Wang, X. (2014). Preparation of magnetic ionic liquid/chitosan/graphene oxide composite and application for water treatment. Int. J. Biol. Macromol. 66, 172-178. doi: 10.1016/j.ijbiomac.2014.02.031

Li, L., Wu, M., Feng, Y., Zhao, F., and Zeng, B. (2016). Doping of three-dimensional porous carbon nanotube-graphene-ionic liquid composite into polyaniline for the headspace solid-phase microextraction and gas chromatography determination of alcohols. Anal. Chim. Acta 948, 48-54. doi: 10.1016/j.aca.2016.11.020

Li, N., Chen, J., and Shi, Y. (2019b). Magnetic nitrogen-doped reduced graphene oxide as a novel magnetic solid- phase extraction adsorbent for the separation of bisphenol endocrine disruptors in carbonated beverages. Talanta 201, 194-203. doi: $10.1016 /$ j.talanta.2019.04.002 
Li, N., Chen, J., and Shi, Y.P. P. (2019a). Magnetic polyethyleneimine functionalized reduced graphene oxide as a novel magnetic sorbent for the separation of polar non-steroidal anti-inflammatory drugs in waters. Talanta 191, 526-534. doi: 10.1016/j.talanta.2018.09.006

Li, N., Jiang, H., Wang, X., Wang, X., Xu, G., Zhang, B., et al. (2018). Recent advances in graphene-based magnetic composites for magnetic solid-phase extraction. $\operatorname{Tr} A C \quad 102, \quad 60-74$. doi: 10.1016/j.trac.2018. 01.009

Li, W., Zhang, J., Zhu, W., Qin, P., Zhou, Q., Lu, M., et al. (2020). Facile preparation of reduced graphene oxide/ZnFe2O4 nanocomposite as magnetic sorbents for enrichment of estrogens. Talanta 208:120440. doi: 10.1016/j.talanta.2019.120440

Liang, X., Wang, S., Liu, S., Liu, X., and Jiang, S. (2012). A novel octadecylsilane functionalized graphene oxide/silica composite stationary phase for high performance liquid chromatography. J. Sep. Sci. 35, 2003-2009. doi: $10.1002 /$ jssc. 201200258

Lim, J. Y., Mubarak, N. M., Abdullah, E. C., Nizamuddin, S., Khalid, M., and Inamuddin (2018). Recent trends in the synthesis of graphene and graphene oxide based nanomaterials for removal of heavy metals-a review. J. Ind. Eng. Chem. 66, 29-44. doi: 10.1016/j.jiec.2018.05.028

Lin, L., Peng, H., and Liu, Z. (2019). Synthesis challenges for graphene industry. Nat. Mater. 18, 520-524. doi: 10.1038/s41563-019-0341-4

Liu, B., and Zhou, K. (2019). Recent progress on graphene-analogous 2D nanomaterials: properties, modeling and applications. Prog. Mater. Sci. 100, 99-169. doi: 10.1016/j.pmatsci.2018.09.004

Liu, G., Huang, X., Lu, M., Li, L., Li, T., and Xu, D. (2019). Facile synthesis of magnetic zinc metal-organic framework for extraction of nitrogen-containing heterocyclic fungicides from lettuce vegetable samples. J. Sep. Sci. 42, 1451-1458. doi: $10.1002 /$ jssc.201801169

Liu, G., Li, L., Xu, D., Huang, X., Xu, X., Zheng, S., et al. (2017). Metalorganic framework preparation using magnetic graphene oxide- $\beta$-cyclodextrin for neonicotinoid pesticide adsorption and removal. Carbohydr. Polym. 175, 584-591. doi: 10.1016/j.carbpol.2017.06.074

Liu, J., Liang, Y., Shen, J., and Bai, Q. (2018). Polymeric ionic liquid-assembled graphene-immobilized silica composite for selective isolation of human serum albumin from human whole blood. Anal. Bioanal. Chem. 410, 573-584. doi: $10.1007 / \mathrm{s} 00216-017-0758-\mathrm{z}$

Liu, M., Ding, X., Wang, X., Li, J., Yang, H., and Yin, Y. (2019). Extraction of DNA from complex biological sample matrices using guanidinium ionic liquid modi fied magnetic nanocomposites. RSC Adv. 9, 23119-23128. doi: 10.1039/C9RA01505A

Liu, W., Zha, J., Meng, X., Wu, J., Sun, C., Qiu, P., et al. (2017). Efficient removal and trace determination of chlorophenols from water using mixed hemi/ad-micelle ionic liquid-coated magnetic graphene oxide and the adsorption mechanism. Anal. Methods 9, 4581-4591. doi: 10.1039/C7AY01241A

Liu, X., Gao, S., Li, X., Wang, H., Ji, X., and Zhang, Z. (2019). Determination of microcystins in environmental water samples with ionic liquid magnetic graphene. Ecotoxicol. Environ. Saf. 176, 20-26. doi: 10.1016/j.ecoenv.2019.03.063

Lu, Q., Guo, H., Zhang, Y., Tang, X., Lei, W., Qi, R., et al. (2020). Graphene oxideFe $3 \mathrm{O} 4$ nanocomposite magnetic solid phase extraction followed by UHPLCMS/MS for highly sensitive determination of eight psychoactive drugs in urine samples. Talanta 206:120212. doi: 10.1016/j.talanta.2019.120212

Lu, Y., Wang, B., Wang, C., Yan, Y., Wu, D., Liang, H., et al. (2019a). A covalent organic framework-derived hydrophilic magnetic graphene composite as a unique platform for detection of phthalate esters from packaged milk samples. Chromatographia 82, 1089-1099. doi: 10.1007/s10337-01903741-w

Lu, Y., Wang, B., Yan, Y., Liang, H., and Wu, D. (2019b). Silica protection-sacrifice functionalization of magnetic graphene with a metal-organic framework (ZIF-8) to provide a solid-phase extraction composite for recognization of phthalate easers from human plasma samples. Chromatographia 82, 625-634. doi: 10.1007/s10337-0183673-3

Luo, J., Gao, Y., Tan, K., Wei, W., and Liu, X. (2016). Preparation of a magnetic molecularly imprinted graphene composite highly adsorbent for 4-nitrophenol in aqueous medium. ACS Sustain. Chem. Eng. 4, 3316-3326. doi: 10.1021/acssuschemeng.6b00367
Luo, J., Huang, J., Cong, J., Wei, W., and Liu, X. (2017). Double recognition and selective extraction of glycoprotein based on the molecular imprinted graphene oxide and boronate affinity. ACS Appl. Mater. Interfaces 9, 7735-7744. doi: 10.1021/acsami.6b14733

Luo, Y.-B., Cheng, J.-S. S., Ma, Q. A., Feng, Y.-Q. Q., and Li, J.-H. H. (2011a). Graphene-polymer composite: extraction of polycyclic aromatic hydrocarbons from water samples by stir rod sorptive extraction. Anal. Methods 3, 92-98. doi: 10.1039/C0AY00624F

Luo, Y.-B., Shi, Z., Gao, Q., and Feng, Y. (2011b). Magnetic retrieval of graphene : extraction of sulfonamide antibiotics from environmental water samples. J. Chromatogr. A 1218, 1353-1358. doi: 10.1016/j.chroma.2011.01.022

Ma, G., Zhang, M., Zhu, L., Chen, H., Liu, X., and Lu, C. (2018). Facile synthesis of amine-functional reduced graphene oxides as modified quick, easy, cheap, effective, rugged and safe adsorbent for multi-pesticide residues analysis of tea. J. Chromatogr. A 1531, 22-31. doi: 10.1016/j.chroma.2017.11.044

Maciel, E. V. S., de Toffoli, A. L., Neto, E. S., Nazario, C. E. D., and Lanças, F. M. (2019). New materials in sample preparation: recent advances and future trends. TrAC 119:115633. doi: 10.1016/j.trac.2019.115633

Madej, K., Jonda, A., Borcuch, A., Piekoszewski, W., Chmielarz, L., and Gil, B. (2019). A novel stir bar sorptive-dispersive microextraction in combination with magnetically modified graphene for isolation of seven pesticides from water samples. Microchem. J. 147, 962-971. doi: 10.1016/j.microc.2019.04.002

Maggira, M., Deliyanni, E. A., and Samanidou, V. F. (2019). Synthesis of graphene oxide based sponges and their study as sorbents for sample preparation of cow milk prior to HPLC determination of sulfonamides. Molecules 24:2086. doi: 10.3390/molecules 24112086

Mahpishanian, S., and Sereshti, H. (2017). One-step green synthesis of $\beta$ cyclodextrin/iron oxide-reduced graphene oxide nanocomposite with high supramolecular recognition capability: application for vortex-assisted magnetic solid phase extraction of organochlorine pesticides residue from honey sam. $J$. Chromatogr. A 1485, 32-43. doi: 10.1016/j.chroma.2017.01.035

Marcinkowski, Ł., Pena-Pereira, F., Kloskowski, A., and Namieśnik, J. (2015). Opportunities and shortcomings of ionic liquids in single-drop microextraction. $\operatorname{Tr} A C$ 72, 153-168. doi: 10.1016/j.trac.2015.03.024

Mejía-Carmona, K., and Lanças, F. M. (2020). Modified graphenesilica as a sorbent for in-tube solid-phase microextraction coupled to liquid chromatography-tandem mass spectrometry. Determination of xanthines in coffee beverages. J. Chromatogr. A 1621:461089. doi: 10.1016/j.chroma.2020.461089

Mohan, V. B., Lau, K., Hui, D., and Bhattacharyya, D. (2018). Graphenebased materials and their composites: a review on production, applications and product limitations. Compos. B Eng. 142, 200-220. doi: 10.1016/j.compositesb.2018.01.013

Moradi, S., Saber-tehrani, M., and Faraji, M. (2019). Simultaneous magnetic solid phase extraction of acidic and basic pesticides using triazinebased polymeric network modified magnetic nanoparticles/graphene oxide nanocomposite in water and food samples. Microchem. J. 146, 630-639. doi: 10.1016/j.microc.2019.01.047

Nawała, J., Dawidziuk, B., Dziedzic, D., Gordon, D., and Popiel, S. (2018). Applications of ionic liquids in analytical chemistry with a particular emphasis on their use in solid-phase microextraction. TrAC 105, 18-36. doi: 10.1016/j.trac.2018.04.010

Ning, F., Peng, H., Li, J., Chen, L., and Xiong, H. (2014). Molecularly imprinted polymer on magnetic graphene oxide for fast and selective extraction of 17ß-estradiol. J. Agric. Food Chem. 62, 7436-7443. doi: 10.1021/jf501845w

Niu, P., Nie, X., Li, Y., Liang, X., Wang, L., and Guo, Y. (2020). Magnetic $\mathrm{N}$-doped 3D graphene-like framework carbon for extraction of cephalexin monohydrate and ceftiofur hydrochloride. Talanta 215:120932. doi: $10.1016 /$ j.talanta.2020.120932

Novoselov, K. S. (2004). Electric field effect in atomically thin carbon films. Science 306, 666-669. doi: 10.1126/science.1102896

Novoselov, K. S., Jiang, D., Schedin, F., Booth, T. J., Khotkevich, V. V., Morozov, S. V., et al. (2005). Two-dimensional atomic crystals. Proc. Natl. Acad. Sci. U. S. A. 102, 10451-10453. doi: 10.1073/pnas. 0502848102

Nurerk, P., Bunkoed, W., Kanatharana, P., and Bunkoed, O. (2018). A miniaturized solid-phase extraction adsorbent of calix[4]arene-functionalized graphene oxide/polydopamine-coated cellulose acetate for the analysis of aflatoxins in corn. J. Sep. Sci. 41, 3892-3901. doi: 10.1002/jssc. 201800440 
Pan, J., Chen, W., Ma, Y., and Pan, G. (2018). Molecularly imprinted polymers as receptor mimics for selective cell recognition. Chem. Soc. Rev. 47, 5574-5587. doi: 10.1039/C7CS00854F

Pang, Y. Q., Chen, X. J., Li, X. Y., Zhang, H. F., Jiang, X.Y., Zhu, F. P., et al. (2019). Magnetic solid-phase extraction of tobacco-specific N-nitrosamines using magnetic graphene composite as sorbent. J. Sep. Sci. 42, 3119-3125. doi: $10.1002 /$ jssc. 201900438

Papageorgiou, D. G., Kinloch, I. A., and Young, R. J. (2017). Mechanical properties of graphene and graphene-based nanocomposites. Prog. Mater. Sci. 90, 75-127. doi: 10.1016/j.pmatsci.2017.07.004

Peierls, R. (1935). Quelques propriétés typiques des corps solides. Ann. l'institut Henri Poincaré 5, 177-122.

Peng, Q., Dearden, A. K., Crean, J., Han, L., Liu, S., Wen, X., et al. (2014). New materials graphyne, graphdiyne, graphone, and graphane: review of properties, synthesis, and application in nanotechnology. Nanotechnol. Sci. Appl. 7, 1-29. doi: $10.2147 /$ NSA.S40324

Pham, T. S. H., Fu, L., Mahon, P., Lai, G., and Yu, A. (2016). Fabrication of $\beta$-cyclodextrin-functionalized reduced graphene oxide and its application for electrocatalytic detection of carbendazim. Electrocatalysis 7, 411-419. doi: 10.1007/s12678-016-0320-3

Pinho, E., Grootveld, M., and Henriques, M. (2014). Cyclodextrins as encapsulation agents for plant bioactive compounds. Carbohydr. Polym. 101, 121-135. doi: 10.1016/j.carbpol.2013.08.078

Qiu, J., Chen, G., Liu, S., Zhang, T., Wu, J., Wang, F., et al. (2016). Bioinspired polyelectrolyte-assembled graphene-oxide-coated C18 composite solid-phase microextraction fibers for in vivo monitoring of acidic pharmaceuticals in fish. Anal. Chem. 88, 5841-5848. doi: 10.1021/acs.analchem.6b00417

Ragavan, K. V., and Rastogi, N. K. (2017). $\beta$-Cyclodextrin capped graphenemagnetite nanocomposite for selective adsorption of bisphenol-A. Carbohydr. Polym. 168, 129-137. doi: 10.1016/j.carbpol.2017.03.045

Ran, X., Yang, L., Qu, Q., Li, S., Chen, Y., Zuo, L., et al. (2017). Synthesis of welldispersive $2.0 \mathrm{~nm}$ Pd-Pt bimetallic nanoclusters supported on $\beta$-cyclodextrin functionalized graphene with excellent electrocatalytic activity. RSC Adv. 7, 1947-1955. doi: 10.1039/C6RA24893D

Razavi, N., and Es, Z. (2019). Curcumin loaded magnetic graphene oxide solid-phase extraction for the determination of parabens in toothpaste and mouthwash coupled with high performance liquid chromatography. Microchem. J. 148, 616-625. doi: 10.1016/j.microc.2019.04.057

Rodríguez-Sánchez, S., Galindo-Iranzo, P., Soria, A. C., Sanz, M. L., QuintanillaLópez, J. E., and Lebrón-Aguilar, R. (2014). Characterization by the solvation parameter model of the retention properties of commercial ionic liquid columns for gas chromatography. J. Chromatogr. A 1326, 96-102. doi: 10.1016/j.chroma.2013.12.020

Rofouei, M. K., Jamshidi, S., Seidi, S., and Saleh, A. (2017). A bucky gel consisting of $\mathrm{Fe} 3 \mathrm{O} 4$ nanoparticles, graphene oxide and ionic liquid as an efficient sorbent for extraction of heavy metal ions from water prior to their determination by ICP-OES. Microchim. Acta 184, 3425-3432. doi: 10.1007/s00604-017-2370-5

Rykowska, I., Ziemblinska, J., and Nowak, I. (2018). Modern approaches in dispersive liquid-liquid microextraction (DLLME) based on ionic liquids: a review. J. Mol. Liq. 259, 319-339. doi: 10.1016/j.molliq.2018.03.043

Šafariková, M., and Šafarik, I. (1999). Magnetic solid-phase extraction. J. Magn. Magn. Mater. 194, 108-112. doi: 10.1016/S0304-8853(98)00566-6

Sarp, G., and Yilmaz, E. (2019). A flower-like hybrid material composed of Fe 3 O 4, graphene oxide and CdSe nanodots for magnetic solid phase extraction of ibuprofen prior to its quantification by HPLC detection. Microchim. Acta 186:744. doi: 10.1007/s00604-019-3875-x

Sereshti, H., Toloutehrani, A., and Rashidi, H. (2020). Determination of cholecalciferol (vitamin D 3) in bovine milk by dispersive micro-solid phase extraction based on the magnetic three-dimensional graphene-sporopollenin sorbent. J. Chromatogr. B 1136:121907. doi: 10.1016/j.jchromb.2019. 121907

Serrano, M., Chatzimitakos, T., Gallego, M., and Stalikas, C. D. (2016). 1-Butyl-3-aminopropyl imidazolium-functionalized graphene oxide as a nanoadsorbent for the simultaneous extraction of steroids and $\beta$-blockers via dispersive solid-phase microextraction. J. Chromatogr. A 1436, 9-18. doi: 10.1016/j.chroma.2016.01.052

Shah, J., and Jan, M. R. (2020). Eco-friendly alginate encapsulated magnetic graphene oxide beads for solid phase microextraction of endocrine disrupting compounds from water samples. Ecotoxicol. Environ. Saf. 190:110099. doi: 10.1016/j.ecoenv.2019.110099

Shamaila, S., Sajjad, A. K. L., and Iqbal, A. (2016). Modifications in development of graphene oxide synthetic routes. Chem. Eng. J. 294, 458-477. doi: 10.1016/j.cej.2016.02.109

Shi, X., Qiao, L., and Xu, G. (2015). Recent development of ionic liquid stationary phases for liquid chromatography. J. Chromatogr. A 1420, 1-15. doi: 10.1016/j.chroma.2015.09.090

Singh, R. K., Kumar, R., and Singh, D. P. (2016). Graphene oxide: strategies for synthesis, reduction and frontier applications. RSC Adv. 6, 64993-65011. doi: 10.1039/C6RA07626B

Sitko, R., Zawisza, B., and Malicka, E. (2013). Graphene as a new sorbent in analytical chemistry. TrAC 51, 33-43. doi: 10.1016/j.trac.2013.05.011

Smith, A. T., LaChance, A. M., Zeng, S., Liu, B., and Sun, L. (2019). Synthesis, properties, and applications of graphene oxide/reduced graphene oxide and their nanocomposites. Nano Mater. Sci. 1, 31-47. doi: 10.1016/j.nanoms.2019.02.004

Solís-Fernández, P., Bissett, M., and Ago, H. (2017). Synthesis, structure and applications of graphene-based 2D heterostructures. Chem. Soc. Rev. 46, 4572-4613. doi: 10.1039/C7CS00160F

Sotolongo, A. C., Martinis, E. M., and Wuilloud, R. G. (2018). An easily prepared graphene oxide-ionic liquid hybrid nanomaterial for micro-solid phase extraction and preconcentration of $\mathrm{Hg}$ in water samples. Anal. Methods 10, 338-346. doi: 10.1039/C7AY02201H

Speltini, A., Sturini, M., Maraschi, F., Consoli, L., Zeffiro, A., and Profumo, A. (2015). Graphene-derivatized silica as an efficient solid-phase extraction sorbent for pre-concentration of fluoroquinolones from water followed by liquid-chromatography fluorescence detection. J. Chromatogr. A 1379, 9-15. doi: 10.1016/j.chroma.2014.12.047

Sun, L. (2019). Structure and synthesis of graphene oxide. Chinese J. Chem. Eng. 27, 2251-2260. doi: 10.1016/j.cjche.2019.05.003

Sun, M., Bu, Y., Feng, J., and Luo, C. (2016). Graphene oxide reinforced polymeric ionic liquid monolith solid-phase microextraction sorbent for high-performance liquid chromatography analysis of phenolic compounds in aqueous environmental samples. J. Sep. Sci. 39, 375-382. doi: 10.1002/jssc.201500904

Sun, M., Cui, P., Ji, S., Tang, R., Wu, Q., Wang, C., et al. (2014). Octadecyl-modified graphene as an adsorbent for hollow fiber liquid phase microextraction of chlorophenols from honey. Bull. Korean Chem. Soc. 35, 1011-1015. doi: 10.5012/bkcs.2014.35.4.1011

Szejtli, J. (2004). Past, present, and future of cyclodextrin research. Pure Appl. Chem. 76, 1825-1845. doi: 10.1351/pac200476101825

Tahmasebi, E. (2018). Adsorption efficiency enhancing of electrospun polycaprolactone nanofibers towards acidic polar drugs through the incorporation of a composite of graphene oxide nanosheets and $\mathrm{Al}$ 30 polyoxocations: a comparative study. Analyst 143, 4684-4698. doi: 10.1039/C8AN01066H

Tan, P., and $\mathrm{Hu}, \mathrm{Y}$. (2017). Improved synthesis of graphene/ $\beta$-cyclodextrin composite for highly efficient dye adsorption and removal. J. Mol. Liq. 242, 181-189. doi: 10.1016/j.molliq.2017.07.010

Tang, H., Wang, Y., Li, S., Wu, J., Li, J., Zhou, H., et al. (2019). Graphene oxide composites for magnetic solid-phase extraction of twelve quinolones in water samples followed by MALDI-TOF MS. Anal. Bioanal. Chem. 411, 7039-7049. doi: 10.1007/s00216-019-02081-w

Tang, S., Liu, S., Guo, Y., Liu, X., and Jiang, S. (2014). Recent advances of ionic liquids and polymeric ionic liquids in capillary electrophoresis and capillary electrochromatography. J. Chromatogr. A 1357, 147-157. doi: 10.1016/j.chroma.2014.04.037

Tang, S., Sun, J., Xia, D., Zang, B., Gao, Y., Chen, C., et al. (2019). In-syringe extraction using compressible and self-recoverable, amphiphilic graphene aerogel as sorbent for determination of phenols. Talanta 195, 165-172. doi: 10.1016/j.talanta.2018.11.038

Tang, T., Cao, S., Xi, C., Li, X., Zhang, L., Wang, G., et al. (2020). Green synthesis of magnetic carbon nanodot graphene oxide hybrid.pdfOptimization by response surface methodology of a dispersive magnetic solid.pdfChitosa. Int. J. Biol. Macromol. 146, 343-352. doi: 10.1016/j.ijbiomac.2019.12.259

Tashakkori, P., Erdem, P., Merdivan, M., and Bozkurt, S. S. (2019). Determination of phthalate esters in water and coffee by solid-phase microextraction using 
vinyl terminated imidazolium based ionic liquid grafted on graphene oxide coatings. ChemistrySelect 4, 2307-2313. doi: 10.1002/slct.201803214

Toffoli, A. L., de, Lanças, F. M., de Toffoli, A. L., Maciel, E. V. S., Fumes, B. H., and Lanças, F. M. (2018). The role of graphene-based sorbents in modern sample preparation techniques. J. Sep. Sci. 41, 288-302. doi: 10.1002/jssc.201 700870

Tu, C., Guo, Y., Dai, Y., Wei, W., and Wang, W. (2019). Determination of chloramphenicol in honey and milk by HPLC coupled with aptamerfunctionalized $\mathrm{Fe}_{3} \mathrm{O}_{4}$ /graphene oxide magnetic solid-phase extraction. J. Food Sci. 84, 3624-3633. doi: 10.1111/1750-3841.14955

Ungku Abdullah, U. A. A., Mohamad Hanapi, N. S., Ibrahim, W. N. W., Saiful, A., Ishak, N. S., and Hamid, R. D. (2019). Rapid magnetic solidphase extraction based on graphene oxide/magnetite nanoparticles for the determination of non-steroidal anti-inflammatory drugs and bisphenol-A in tap water U.A.A. Asian J. Chem. 31, 1294-1300. doi: 10.14233/ajchem.20 19.21899

Vadivel, D., Speltini, A., Zeffiro, A., Bellani, V., Pezzini, S., Buttafava, A., et al. (2017). Reactive carbons from Kraft lignin pyrolysis: stabilization of peroxyl radicals at carbon/silica interface. J. Anal. Appl. Pyrolysis 128, 346-352. doi: 10.1016/j.jaap.2017.09.016

Vasconcelos Soares Maciel, E., Henrique Fumes, B., Lúcia de Toffoli, A., and Mauro Lanças, F. (2018). Graphene particles supported on silica as sorbent for residue analysis of tetracyclines in milk employing microextraction by packed sorbent. Electrophoresis 39, 2047-2055. doi: 10.1002/elps.201800051

Walden, P. (2003). Academician pavel ivanovich walden (on 140th anniversary of his birthday). Russ. J. Appl. Chem. 76, 1186-1190. doi: 10.1023/A:1026399420965

Wang, C., Li, T., Liu, Z., Guo, Y., Li, C., Dong, C., et al. (2016). An ultrasensitive sensor based on $\beta$-cyclodextrin modi fi ed magnetic graphene oxide for detection of tryptophan. J. Electroanal. Chem. 781, 363-370. doi: $10.1016 /$ j.jelechem.2016.07.028

Wang, N., Yu, H., and Shao, S. (2016). Preparation of a graphene oxide/silica composite modified with nitro-substituted tris(indolyl)methane as a solidphase extraction sorbent for the extraction of organic acids. J. Sep. Sci. 39, 1700-1708. doi: $10.1002 /$ jssc. 201501362

Wang, X., Li, G., and Row, K. H. (2017a). Graphene and graphene oxide modified by deep eutectic solvents and ionic liquids supported on silica as adsorbents for solid-phase extraction. Bull. Korean Chem. Soc. 38, 251-257. doi: $10.1002 /$ bkcs. 11074

Wang, X., Li, G., and Row, K. H. (2017b). Magnetic graphene oxide modified by imidazole-based ionic liquids for the magnetic-based solid-phase extraction of polysaccharides from brown alga. J. Sep. Sci. 40, 3301-3310. doi: $10.1002 /$ jssc. 201700393

Wang, X., Liu, B., Lu, Q., and Qu, Q. (2014). Graphene-based materials: fabrication and application for adsorption in analytical chemistry. J. Chromatogr. A 1362, 1-15. doi: 10.1016/j.chroma.2014.08.023

Wang, Y., Ou, Y., Xie, S., Chen, D., Wang, X., Pan, Y., et al. (2019). Magnetic graphene solid-phase extraction for the determination of 47 kinds of non-steroidal anti-inflammatory drug residues in animal food with liquid chromatography tandem mass spectrometry. Food Anal. Methods 12, 1346-1368. doi: 10.1007/s12161-019-01440-8

Welton, T. (2018). Ionic liquids: a brief history. Biophys. Rev. 10, 691-706. doi: 10.1007/s12551-018-0419-2

Wu, J., Zhao, H., Xiao, D., Chuong, P. H., He, J., and He, H. (2016). Mixed hemimicelles solid-phase extraction of cephalosporins in biological samples with ionic liquid-coated magnetic graphene oxide nanoparticles coupled with high-performance liquid chromatographic analysis. J. Chromatogr. A 1454, 1-8. doi: 10.1016/j.chroma.2016.05.071

Wu, Q., Feng, C., Wang, C., and Wang, Z. (2013). A facile one-pot solvothermal method to produce superparamagnetic graphene- $\mathrm{Fe}_{3} \mathrm{O}_{4}$ nanocomposite and its application in the removal of dye from aqueous solution. Colloids Surf. $B$ Biointerf. 101, 210-214. doi: 10.1016/j.colsurfb.2012.05.036

Xian, Y., Liang, M., Wu, Y., Wang, B., Hou, X., Dong, H., et al. (2020). Fluorine and nitrogen functionalized magnetic graphene as a novel adsorbent for extraction of perfluoroalkyl and polyfluoroalkyl substances from water and functional beverages followed by HPLC-Orbitrap HRMS determination. Sci. Total Environ. 723:138103. doi: 10.1016/j.scitotenv.2020. 138103
Xiao, R., Wang, S., Hassan, M., Idris, H., Shan, D., Chen, J., et al. (2019). Three-dimensional hierarchical frameworks based on molybdenum disulfide-graphene oxide-supported magnetic nanoparticles for enrichment fluoroquinolone antibiotics in water. J. Chromatogr. A 1593, 1-8. doi: 10.1016/j.chroma.2019.02.005

Xie, X., Ma, X., Guo, L., Fan, Y., Zeng, G., Zhang, M., et al. (2019). Novel magnetic multi-templates molecularly imprinted polymer for selective and rapid removal and detection of alkylphenols in water. Chem. Eng. J. 357, 56-65. doi: 10.1016/j.cej.2018.09.080

Xiong, Y., Lu, Z., Wang, D., Yang, M. O., and Guo, H. (2019). Application of polydopamine functionalized magnetic graphene in triazole fungicides residue analysis. J. Chromatogr. A 1614:460725. doi: 10.1016/j.chroma.2019.460725

$\mathrm{Xu}$, L., Feng, J., Liang, X., Li, J., and Jiang, S. (2012). C18 functionalized graphene oxide as a novel coating for solid-phase microextraction. J. Sep. Sci. 35, 1531-1537. doi: 10.1002/jssc.201200124

Yang, X., Hu, Y., Li, G., and Zhang, Z. (2015). Acrylamide-functionalized graphene micro-solid-phase extraction coupled to high-performance liquid chromatography for the online analysis of trace monoamine acidic metabolites in biological samples. J. Sep. Sci. 38, 1380-1387. doi: 10.1002/jssc.201401432

Yang, X., Zhang, X., Ma, Y., Huang, Y., and Chen, Y. (2009). Superparamagnetic graphene oxide- $\mathrm{Fe} 3 \mathrm{O} 4$ nanoparticles hybrid for controlled targeted drug carriers. J. Mater. Chem. 86, 2710-2714. doi: 10.1039/b821416f

Yavuz, E., Tokalioglu, S., and Patat, S. (2018). Dispersive solid-phase extraction with tannic acid functionalized graphene adsorbent for the preconcentration of trace beryllium from water and street dust samples. Talanta 190, 397-402. doi: 10.1016/j.talanta.2018.08.001

Ye, N., and Shi, P. (2015). Applications of graphene-based materials in solidphase extraction and solid-phase microextraction. Sep. Purif. Rev. 44, 183-198. doi: 10.1080/15422119.2014.912664

Yilmaz, E., and Sarp, G. (2020). Graphene-like MoS 2 -modified magnetic Cdot nanoflowers: an efficient magnetic solid-phase extraction adsorbent for monitoring of trace amounts of ibuprofen. Anal. Methods 12, 1570-1578. doi: 10.1039/C9AY02752A

Yu, H., Merib, J., and Anderson, J. L. (2016). Faster dispersive liquidliquid microextraction methods using magnetic ionic liquids as solvents. $J$. Chromatogr. A 1463, 11-19. doi: 10.1016/j.chroma.2016.08.007

Yu, L., Ma, F., Zhang, L., and Li, P. (2019). Determination of aflatoxin B1 and B2 in vegetable oils using Fe3O4/rGO magnetic solid phase extraction coupled with high-performance liquid chromatography fluorescence with post-column photochemical derivatization. Toxins. 11:621. doi: 10.3390/toxins11110621

Yu, M., Wang, L., Hu, L., Li, Y., Luo, D., and Mei, S. (2019). Recent applications of magnetic composites as extraction adsorbents for determination of environmental pollutants. Trends Anal. Chem. 119:115611. doi: 10.1016/j.trac.2019.07.022

Yuvali, D., Narin, I., Soylak, M., and Yilmaz, E. (2020). Green synthesis of magnetic carbon nanodot/graphene oxide hybrid material (Fe3O4@ C-nanodot @ GO) for magnetic solid phase extraction of ibuprofen in human blood samples prior to HPLC-DAD determination. J. Pharm. Biomed. Anal. 179:113001. doi: 10.1016/j.jpba.2019.113001

Zhang, H., and Lee, H. K. (2011). Plunger-in-needle solid-phase microextraction with graphene-based sol-gel coating as sorbent for determination of polybrominated diphenyl ethers. J. Chromatogr. A 1218, 4509-4516. doi: 10.1016/j.chroma.2011.05.016

Zhang, H., Wu, X., Yuan, Y., Han, D., Qiao, F., and Yan, H. (2018). An ionic liquid functionalized graphene adsorbent with multiple adsorption mechanisms for pipette-tip solid-phase extraction of auxins in soybean sprouts. Food Chem. 265, 290-297. doi: 10.1016/j.foodchem.2018.05.090

Zhang, Q., Zhou, D., Li, F., Wang, Y., and Yang, F. (2019). Extraction of nucleobases, nucleosides and nucleotides by employing a magnetized graphene oxide functionalized with hydrophilic phytic acid and titanium (IV) ions. Mikrochim. Acta 186:187. doi: 10.1007/s00604-019-3308-x

Zhang, R., Su, P., and Yang, Y. (2014). Microwave-assisted preparation of magnetic nanoparticles modified with graphene oxide for the extraction and analysis of phenolic. J. Sep. Sci. 37, 3339-3346. doi: 10.1002/jssc.201400767

Zhang, S., Yao, W., Zhou, C., Wang, J., and Zhao, H. (2019). Fabrication of magnetic zeolitic imidazolate framework-7 supported graphene oxide for the extraction of fungicides from environmental water and soil samples. Int. J. Environ. Anal. Chem. 1-10. doi: 10.1080/03067319.2019.1670821 
Zhang, Y., Zhao, Y.-G. G., Chen, W.-S. S., Cheng, H.-L. L., Zeng, X.-Q. Q., and Zhu, Y. (2018). Three-dimensional ionic liquid-ferrite functionalized graphene oxide nanocomposite for pipette-tip solid phase extraction of 16 polycyclic aromatic hydrocarbons in human blood sample. J. Chromatogr. A 1552, 1-9. doi: 10.1016/j.chroma.2018.03.039

Zhao, P., Wang, Z., Gao, X., Guo, X., and Zhao, L. (2019). Simultaneous enantioselective determination of 22 chiral pesticides in fruits and vegetables using chiral liquid chromatography coupled with tandem mass spectrometry. Food Chem. 277, 298-306. doi: 10.1016/j.foodchem.2018.10.128

Zheng, S., Tu, Q., Li, S., and Mi, B. (2017). Swelling of graphene oxide membranes in aqueous solution : characterization of interlayer spacing and insight into water. ACS Nano 6, 6440-6450. doi: 10.1021/acsnano.7b02999

Zhou, J., Wang, R., and Chen, Z. (2019). Stir bar sorptive extraction with a graphene oxide framework-functionalized stainless-steel wire for the determination of Sudan dyes in water samples. Anal. Methods 11, 2050-2056. doi: 10.1039/C9AY00321E

Zhou, T., Ding, L., Che, G., Jiang, W., and Sang, L. (2019). Recent advances and trends of molecularly imprinted polymers for specific recognition in aqueous matrix: preparation and application in sample pretreatment. $\operatorname{Tr} A C 114,11-28$. doi: 10.1016/j.trac.2019.02.028

Zhou, X., Zhang, Y., Huang, Z., Lu, D., Zhu, A., and Shi, G. (2016). Ionic liquids modified graphene oxide composites: a high efficient adsorbent for phthalates from aqueous solution. Sci. Rep. 6:38417. doi: 10.1038/srep38417
Zhou, Y., Zhao, M., and Meng, Z. (2019). A magnetic graphene-like MoS 2 nanocomposite for simultaneous preconcentration of multi-residue herbicides prior to UHPLC with ion trap mass spectrometric detection. Mikrochim. Acta 186:486. doi: 10.1007/s00604-019-3536-0

Zhu, Q.-Y., Zhang, Q.-Y., Cao, J., Cao, W., Xu, J.-J., and Peng, L.-Q. (2016). Cyclodextrin-assisted liquid-solid extraction for determination of the composition of jujube fruit using ultrahigh performance liquid chromatography with electrochemical detection and quadrupole time-of-flight tandem mass spectrometry. Food Chem. 213, 485-493. doi: 10.1016/j.foodchem.2016. 06.115

Conflict of Interest: The authors declare that the research was conducted in the absence of any commercial or financial relationships that could be construed as a potential conflict of interest.

Copyright (c) 2020 Maciel, Mejía-Carmona, Jordan-Sinisterra, da Silva, Vargas Medina and Lanças. This is an open-access article distributed under the terms of the Creative Commons Attribution License (CC BY). The use, distribution or reproduction in other forums is permitted, provided the original author(s) and the copyright owner(s) are credited and that the original publication in this journal is cited, in accordance with accepted academic practice. No use, distribution or reproduction is permitted which does not comply with these terms. 